Article

\title{
Security Assessment of Urban Areas through a GIS-Based Analysis of Lighting Data Generated by IoT Sensors
}

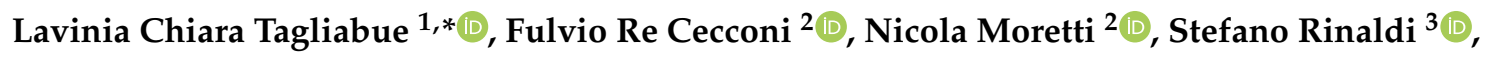 \\ Paolo Bellagente ${ }^{3}(1)$ and Angelo Luigi Camillo Ciribini ${ }^{1}$ \\ 1 Department of Civil, Environmental, Architectural Engineering and Mathematics, University of Brescia, \\ 25123 Brescia, Italy; angelo.ciribini@unibs.it \\ 2 Department of Architecture, Build Environment and Construction Engineering, Politecnico di Milano, \\ 20133 Milan, Italy; fulvio.rececconi@polimi.it (F.R.C.); nicola.moretti@polimi.it (N.M.) \\ 3 Department of Information Engineering, University of Brescia, 25123 Brescia, Italy; \\ stefano.rinaldi@unibs.it (S.R.); p.bellagente@unibs.it (P.B.) \\ * Correspondence: chiara.tagliabue@polimi.it; Tel.: +39-02-2399-6018
}

Received: 27 January 2020; Accepted: 12 March 2020; Published: 23 March 2020

\begin{abstract}
The current perspective about urban development expects $70 \%$ of energy consumption will be concentrated in the cities in 2050. In addition, a growing density of people in the urban context leads to the need for increased security and safety for citizens, which imply a better lighting infrastructure. Smart solutions are required to optimize the corresponding energy effort. In developing countries, the cities' lighting is limited and the lighting world map is strongly significant about the urban density of the different areas. Nevertheless, in territories where the illumination level is particularly high, such as urban contexts, the conditions are not homogenous at the microscale level and the perceived security is affected by artificial urban lighting. As an example, $27.2 \%$ of the families living in the city of Milan, ombardy Region, Italy, consider critical the conditions of lighting in the city during the night, although the region has diffused infrastructure. The paper aims to provide a local illuminance geographic information system (GIS) mapping at the neighborhood level that can be extended to the urban context. Such an approach could unveil the need to increase lighting to enhance the perceived safety and security for the citizens and promote a higher quality of life in the smart city. Lighting mapping can be matched with car accident mapping of cities and could be extended to perceived security among pedestrians in urban roads and green areas, also related to degradation signs of the built environment. In addition, such an approach could open new scenarios to the adaptive street lighting control used to reduce the energy consumption in a smart city: the perceived security of an area could be used as an additional index to be considered during the modulation of the level of the luminosity of street lighting. An example of a measurement set-up is described and tested at the district level to define how to implement an extensive monitoring campaign based on an extended research schema.
\end{abstract}

Keywords: GIS; open data; security mapping; lighting mapping; perceived security; user centered design; mobile sensing; urban sensing; IoT sensors

\section{Introduction}

Urban centers are becoming increasingly attractive for people in developing and developed countries and the transitions of people toward the cities has rapidly grown in the past 40 years. In 1950, in general about $2 / 3$ of the world population lived in rural settlements and $1 / 3$ was living in urban areas to exploit working conditions and opportunities. The share of the global population living in urban 
areas has increased from one third in 1960 to $55 \%$ (4.1 billion people) in 2018 [1]. The world's urban population is now increasing by 60 million persons per year, about three times the increase registered in the rural population [2]. Growing urbanization is a consequence of the new births in urban zones and of continued migration of people coming from the rural surroundings. These movements are also enhancing the sprawl of urban spaces as before rural peri-urban settlements were combined into nearby cities and secondary cities, connected by commerce activities developed in larger urban centers [3]. The process of urbanization is expected to strongly endure in the next century. By 2030, it is projected that nearly 5 billion of the world's 8.1 billion people will live in urban developments, which means $61 \%$ of the population. The less-developed regions will be more than $57 \%$ urban. Latin America and the Caribbean will actually have a greater percentage of inhabitants living in cities than in Europe [4] because of the disparity of conditions and services that people can find in the city centers. In the past, the movement from rural areas to the cities could guarantee better living conditions, however there is scientific evidence that now this assumption is not always valid. There is a high disparity in living conditions between downtown and the surroundings in US [5], European and Asian cities [6]. Worldwide, the number of metropolises with 10 million or more inhabitants is increasing rapidly, configuring new 'megacities' located in the less-developed areas of the world. In 1960, only New York and Tokyo had more than 10 million people, by 1999 the number of cities with more than 10 million people around the world was 17, with 13 located in developing regions [7].

Currently, urban centers occupy less than $5 \%$ of the world's mainland, using over two-thirds of the total energy, and they are responsible for over $70 \%$ of $\mathrm{CO}_{2}$ emissions, according to the $\mathrm{C} 40$ Cities Climate Leadership Group [8]. In 2050, the outlook is that 6 billion people will live in urban zones, worldwide. Thus, innovation in urban infrastructure and technology is essential when addressing sustainable and low-impact solutions to support anthropic activities and urban growth and to reduce the cities' impact. As an example, by 2030, greenhouse gas (GHG) emissions could be reduced by up to 1.5 billion metric tons $\mathrm{CO}_{2 \mathrm{eq}}$ annually, mainly through a massive transformative change in the transport systems in the world's 724 largest cities [9]. The availability of a pervasive communication infrastructure, wireless [10] or cable [11], in the city of the future is a prerequisite to enable services and solutions to improve sustainability in the use of the energy resources [12,13].

How to manage this incomparable urban expansion in following years is likely to decide the outcome of the sustainability endeavors that are spreading through different sectors [14]. The global trends of urbanization in the first decades of the 21st century are meaningfully transformed from the preceding experiences in terms of urban change. For instance, urbanization is taking place at lower levels of economic development and the majority of future urban population increase will take place in developing countries where the aggregation of people in the urban centers often occurs in informal settlements [15].

These kinds of urban forms of organization are taken in consideration to promote upgrading and regeneration of social conditions and health improvements, considering that in some cases the term slums is used to define such casual and degraded environment where security issues are one of the first matters to consider [16]. The expansion of urban areas is on average twice as fast as urban population with significant concerns for GHG emissions and climate change effect, as mentioned before [17] but also for other kinds of issues and pollution problems related to urban aggregation (i.e., air, soil, water, light pollution).

The present research focuses on outdoor artificial lighting, a variable that is closely associated with urbanization because it has interdependencies and outcome at different levels: energy issues, social impacts, use of the city, and psychological perceptions of security. Outdoor artificial lighting is strongly connected with urbanization and anthropic development of territory [18]. The use of lighting in the urban context is extensively adopted in large urban centers and dark areas are experiences as disturbing by citizens while in rural areas people are used to moving in darker areas.

Additionally, lighting is strongly related to the assessment of safety related to traffic management [19] and people security in the cities. In particular, the lighting system has a strong 
impact on vehicle accidents, as clearly demonstrated in [20-22]. The correlation between the quality of the light system and the number of car accidents is well investigated in the literature [23-25]. A low level of or inadequate street lighting is among the first cause of road accident because it has a strong impact on the attention of the drivers. For this reason, the best practice for the design of a new streetlight infrastructure takes into consideration several parameters, including the typology of the road (main or subsidiary), the typical users of the road and the presence of pedestrian and bicycle [26]. The importance of monitoring the quality of light for preventing road accidents is demonstrated in previous research work [27].

The research shows that financial savings from reduced crimes through improved lighting significantly overcame the financial costs of the upgraded street lighting. A meta-analysis found that improved lighting led to reductions in crime of $20 \%$ in experimental areas compared with control areas.

However, night-time crimes did not decrease more than daytime crimes, and a theory focusing on the role of street lighting in increasing community pride seems more plausible than a theory focusing on amplified surveillance, supporting the regenerative role of lighting in the urban areas. Also ecological systems are directly affected by lighting pollution [28] whilst indirect effects are registered on economics [29] and carbon emissions [30] related to urban aggregation and population growth. The weight of lighting in the energy consumption of the diverse countries varies even if it can reach $40 \%[31,32]$ of the total energy consumption of the city with an environmental impact ranging from $13 \%$ to $37 \%$ of GHG emissions for the municipal sector [33].

Given the wide-ranging sustainability inferences of the rise of artificial lighting, research programs are evolving that inspect these phenomena from a range of disciplinary viewpoints. Nonetheless, strategies and policies for the artificial lighting management [34] are less complete than might be predictable [35]. The absence of high-resolution mapping of artificial lighting is progressively documented as an important barrier to related research and management. In contrast, the remote sensing of nocturnal lighting offers an accurate, economical, and straightforward way to map the global distribution and density of developed areas [36]. Datasets exist globally at a coarse spatial $(\sim 3 \mathrm{~km})$ and spectral resolution, allowing us to understand the broad variations in urban lighting [37] but sub-city patterning cannot be explored effectively [38,39]; however, important correlations can be found between population, road density and lengths, and people's incomes. Numerous satellite images are available from the International Space Station with a spatial resolution of up to $60 \mathrm{~m}$. Although these images are starting to be used to detect demographic patterns within urban areas, and in principle, such a mosaic image could also be used to automatically identify and classify the different lights of the city, in practice, individual lamps still cannot be identified [40] and there are some difficulties associated with imaging light pollution: large dynamic range, rapid motion of the sensors, need to sample a large area in a short period of time (requiring a large field of view, FOV).

Finer spatial resolution data do exist, but typically have a limited spatial extent [41] along a landscape modification gradient where the three following phenomena have been recognized [42]: (1) patch density increases exponentially; (2) the regularity of patch shape increases; (3) landscape connectivity decreases [43,44]. These patterns have been constantly supported for urbanizing landscapes throughout the world, however this hinders the development of a robust evidence base to sustain urban lighting policies, as cities can be highly heterogeneous even at fine spatial scales [44]. For example, little is known about how lighting varies with urban land use [45] or alongside built density gradients. Upgraded baseline urban lighting maps are similarly required in order to apply the outcomes of published lighting research [46], to implement existing planning guidance on urban lighting zones, [47], to implement planning agreements and legislation standards related to lighting nuisance [48] and to monitor changes over time. Consequently, we need confident lighting datasets at the city scale; and with a spatial and spectral resolution that should be sufficient to advance lighting research and the development of planning and governance of urban lighting.

The aim of the current research work is to remedy to the current lack of lighting data in urban areas with a proper spatial resolution. Lighting data are missing because measurement campaigns are 
generally expensive, and this is because they involve several technicians moving around different area of cities (and in particular the most unsafe parts of them) during the night with proper measurement devices and the logging of this data in databases. The proposed approach tries to automate this process thanks to the use of a geographic information system (GIS)-based informative system, integrated with lighting data generated by mobile Internet of Things (IoT) sensors The data generated by the IoT sensors can be automatically inserted in a GIS system. Such an approach allows data to be correlated about lighting quality with respect to the perceived level of security and with quantitative data about car accidents and security events. The integration of IoT sensors with the remote GIS system is performed using state of the art IoT protocols [49]. At the present, a measurement prototype based on the Arduino microcontroller has been designed. The IoT sensor is mounted on a mobile mechanical structure which allows easy movement of the sensors in urban areas. The IoT sensor is equipped with off-the-shelf light sensors based on a photodetector. The use of an appropriate sensor calibrated using a V-lambda filter and using cosine correction response input optics, as required by the international norm CIE-194:2011 [50], will provide more accurate light measurement but is out of the scope of the current research work. In fact, as mentioned above, the main contribution of the current research lies in the definition of a GIS-based methodology to analyze and correlate data, more than in the proposal of a new measurement of light sensors.

\section{The Lighting System in Urban Area}

\subsection{Urban Lighting Typologies and Drawbacks}

The extensive use of outdoor lighting is quite recent, tracing its origins to the electric light bulb commercialized by Thomas Edison in the early 1880s. The artificial nocturnal lighting enables a remote sensing of atrophic activities with a level of detail depending on some cultural variations in the quantity and quality of lighting in different countries. It is possible to underline a notable level of correspondence in lighting technology and lighting levels around the world. The key factor affecting the quantity of lighting is wealth, which means that regions with high per capita income install much more lighting than those with a lower per capita income. Even within wealthy regions, however, lighting technology (i.e., lamps and lighting fixtures) is increasingly changing as growing pressure is promoted to shrink night-time sky brightness and save energy. In particular, the huge impact of lighting systems in term of energy consumption required the definition of proper performance indicators to identify the optimal energy/lighting tradeoff [51].

The more environmentally friendly lamps are the low-pressure sodium models, followed by high-pressure sodium. The most polluting are the lamps with a strong blue emission, like metal halide and white light-emitting diodes (LEDs) [44]. The shifting from the now broadly used sodium lamps to white lamps (MH and LEDs) would produce an increase of pollution in the scotopic and melatonin suppression bands of more than five times the present levels, supposing the same photopic installed flux. This upsurge will aggravate known and likely unknown effects of light pollution on human health, environment and on visual perception.

The suppression of melatonin could increase risk of breast cancer through disruption of circadian cycles and studies on LAN (light-at-night) theory are ongoing [52] and solutions to mitigate the issues are crucial to preserve human health. Lighting is also connected with contemporary culture and amenity concepts notwithstanding light pollution has been described as "one of the most rapidly increasing alterations to the natural environment;" an issue whereby "mankind is proceeding to envelop itself in a luminous fog" [53,54].

\subsection{Urban Lighting as Development Indicator}

Researches on this topic showed as remotely sensed lighting data can be assumed to predict both urban extension [55] considering borders and occupied territory [56] encouraging agreement between lighted areas and various definitions of urban extent [57]. For example, conurbations greater than 
$80 \mathrm{~km}$ of diameter account for $<1 \%$ of the analyzed settlements but describe about half the total lighted area worldwide. The area/perimeter distributions designate that urban areas become progressively dendritic while growing. Studies about lighted areas with built areas estimated from Landsat imagery in a sample of 17 cities showed that lighted areas are regularly larger than even maximum estimated built areas for almost all cities in every light dataset. Thresholds $>90 \%$ can often reunite lighted area with built area in the datasets dating from 1994/1995 nevertheless there is not one level that fits the majority of the sample cities.

Outdoor lighting can also provide an estimation of the population distribution, when rough spatial scales are accepted; the Defense Meteorological Satellite Program's Operational Linescan System (DMSP-OLS)-based research provided an approximated assessment of the world population that could demonstrate a $6 \%$ of discrepancy with the correct value, using the night-time satellite imagery and the rate of urbanization of the different nations [58].

With increased urbanization, the spatial coverage and intensity of artificial light pollution seem to be growing [21,59]; furthermore, the night sky spectrum is correspondingly shifting due to the replacement of urban lighting infrastructure [60]. Lighting enables citizens to experience the built environment and research into the effect on urban lighting on behavior are trying to unveil the outcomes related to environmental psychology and social interaction [61].

Lighting has strong cultural link to ideas of modernity and safety whilst developing land-use strategies to contain lighting pollution can lead to energy and economic saving, mitigation of climate change as well as preservation of biodiversity and ecosystem services dependent on natural darkness [62] (Figure 1).

Thus a multi-layered evaluation is needed. The artificial lighting is a demonstration of progress, giving people wider options about where, when and how long their activities can be performed. Nevertheless, lighting has direct effects on health [63] and sector studies demonstrate that the amount of pollution is strongly dependent on the spectral characteristics of the lamps [64].

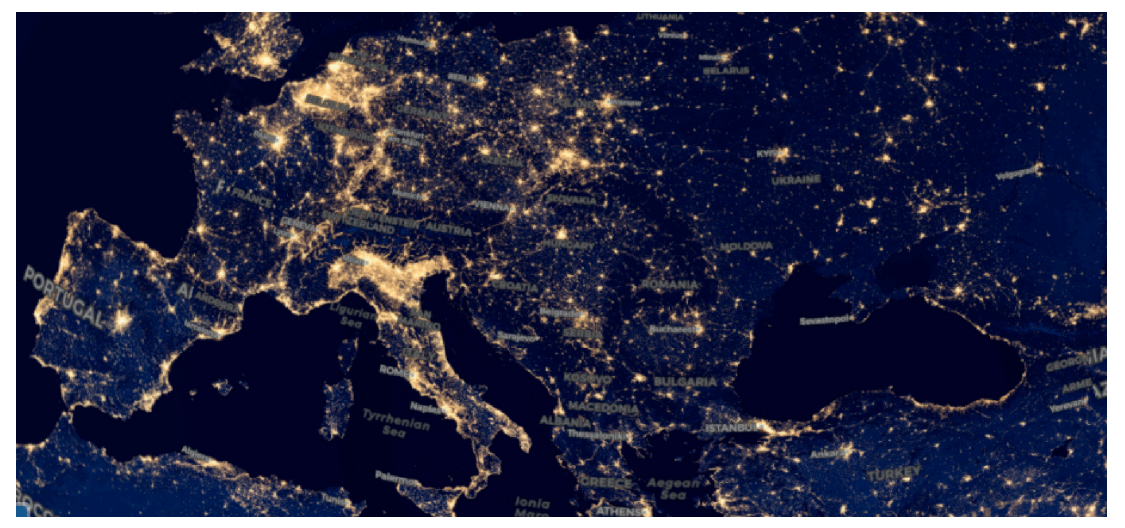

Figure 1. Night view of Europe where lighting depicts the urban areas and main connections [44,65].

\subsection{Urban Lighting Renovation}

The increasing urbanization has led to the request of more and better data at the urban level. Some examples of lighting renovation, such as [66], under European project funding framework, showed high level of possible improvement through local policies to reduce the installed power and the number of lamps achieving consistent cost (average value 60\%) and energy savings (average value $54 \%$ ) results of the light renovation (Figure 2).

The environmental impact reduction ranges depending on the extension of the renovation intervention (from 4.7 up to $138 \mathrm{kgCO}_{2 \mathrm{eq}}$ ). The number of lamps shows an average reduction of $25 \%$ with cases where no reduction is registered up to $72 \%$. It is worth noting that the luminaries points undergone to an average reduction of $0.5 \%$ with a maximum value of $6.9 \%$ (Figure 3). Recent research 
work [67] suggests alternative refurbishment design based on energy prices, able to optimize the investment costs.

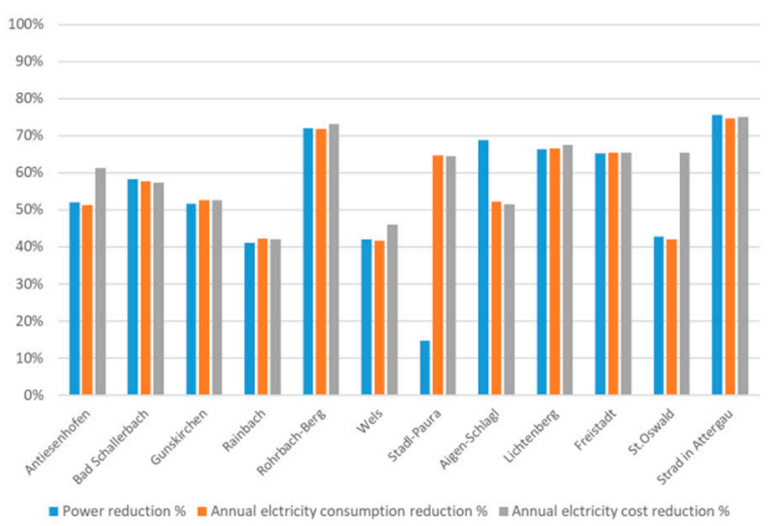

(a)

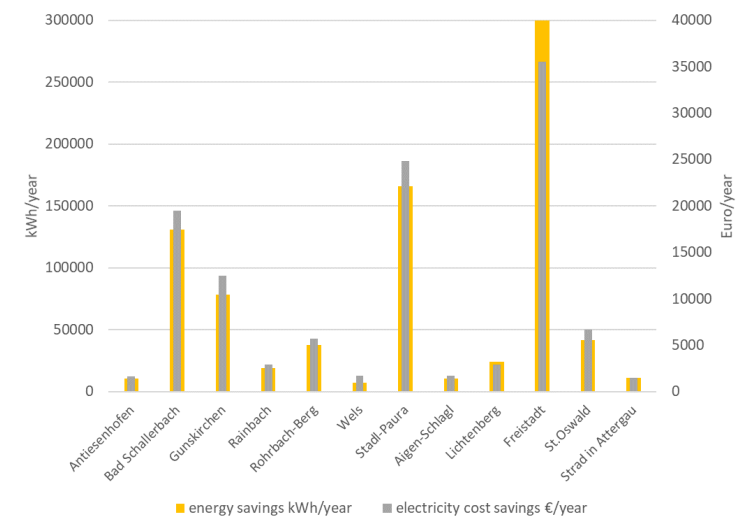

(b)

Figure 2. (a) Percentage of reduction of installed power for artificial outdoor lighting, annual consumption reduction and annual electricity cost reduction in the European renovation project Streetlight EPC (Energy Performance Contracting) [66] in Austria; (b) energy saving and electricity cost saving in the same cities of the mentioned project.

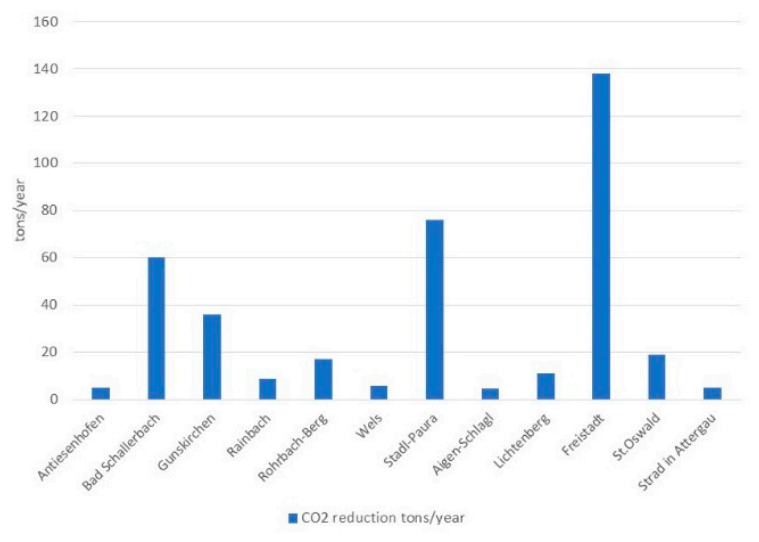

(a)

Figure 3. Cont. 


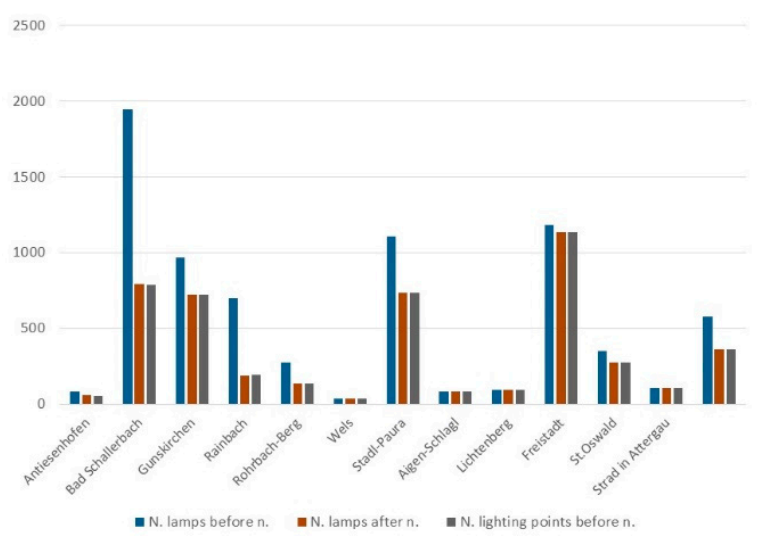

(b)

Figure 3. (a) (Global Warming Potential (GWP) emission reduction in tons of $\mathrm{CO}_{2}$ for the Austrian projects in the European renovation project Streetlight EPC [66]; (b) number of lamps before and after the renovation and luminaires points of light before in the same cities. The luminaires points after the renovation are the same value reported for the new number of lamps.

\section{The Proposed Solution}

As well-known from the literature [68,69], GIS systems are widely used to store and to correlate information regarding several aspect of urban infrastructure, including the state of the pavements alongside the roads, the electrical grid and much more information. GIS can be used not only to visualize the data in thematic maps but, by using properly queries, it is possible to correlate spatially and temporally the data about "road accidents" with "luminosity data", especially if the luminosity data are periodically updated.

A method for the collection, processing and representation of the light intensity data through the use of IoT sensors and GIS has been developed and presented in the following section. This method is part of a wider research framework described in Figure 4.

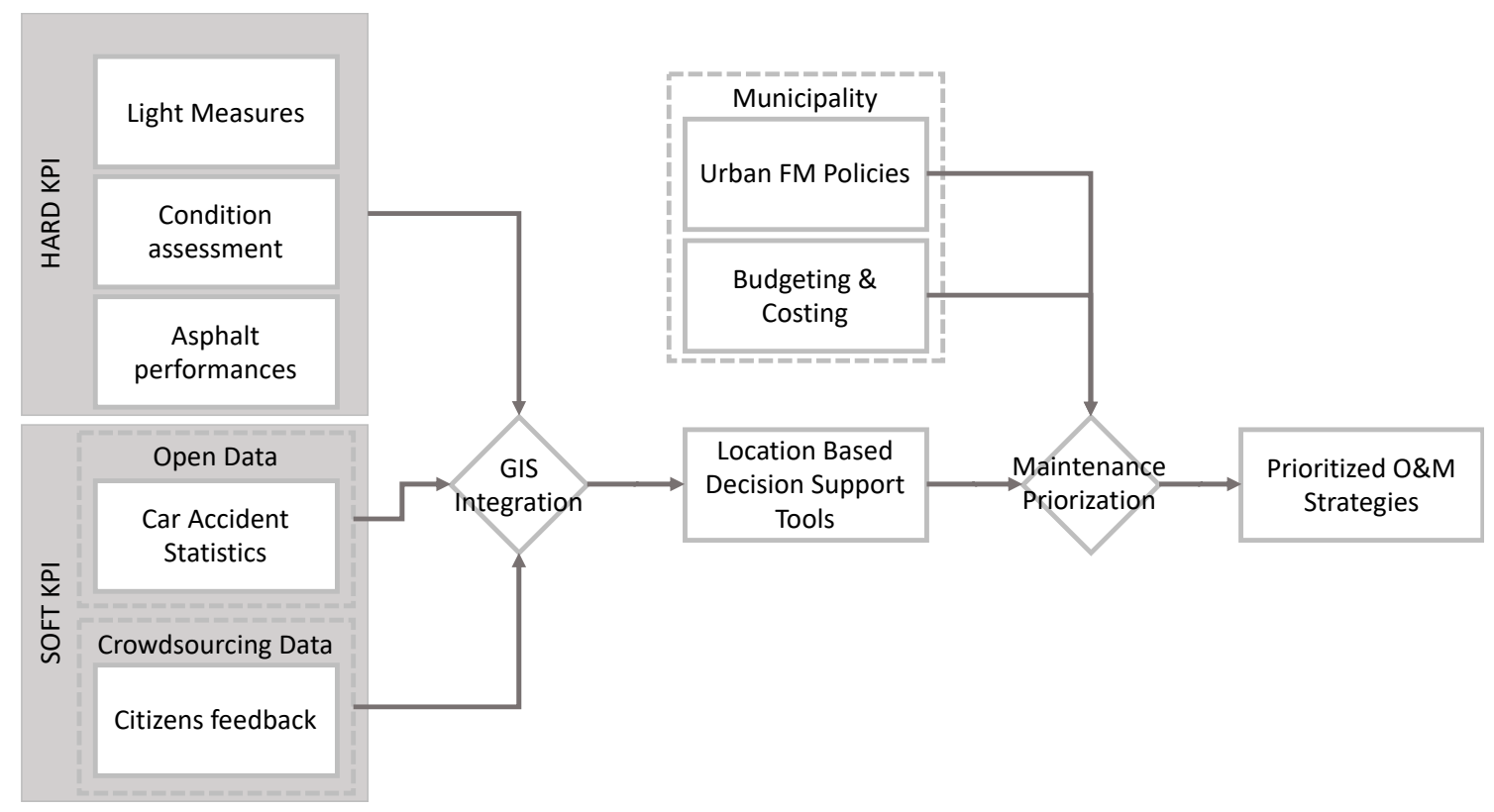

Figure 4. The workflow of the proposed approach.

The idea concerns the development of a location-based decision support system (DSS), able to support decisions on operations maintenance and repair at the urban level. Data are collected from 
different sources: hard key performance indicators (KPIs) concerning technical and measurable data providing information directly related to the safety in the urban environment, and soft KPIs calculated from open data and the crowdsourcing campaign [70], allowing us to capture information impacting on safety issues, even though in an indirect manner. Since the described phenomena belong to the built environment and urban domain, information is collected and integrated in a GIS through which data processing and visualization can be carried out and relations unveiled. These tools allow quantitative and qualitative analysis, data mapping and representations, are include in a location-based DSS which can be related to policies at the municipality level, to obtain informed decisions on prioritization of operations, maintenance and repair $(\mathrm{OM} \& \mathrm{R})$ procedures. This process allows $\mathrm{OM} \& \mathrm{R}$ to be optimized when the resources (time, budget and people) are scarce and have to be optimized and prioritized.

In this article only one part of the wider research schema depicted in Figure 4 has been addressed, since the implementation of the procedures and tools employed for the development of the location-based DSS can be carried out gradually. This article focuses on the collection of data related to the technical performances of the urban component of lighting, data processing through GIS and the development of data analysis and visualization through GIS, integrating databases from different open sources.

\subsection{Urban Car Accidents and Fatalities: Data Availability}

The present research focus on the urban lighting related to security and safety issues and data about the accidents. European data are widely available [71] and report accident data in different countries underlining a trend of reduction in the last decade (the data are available from 2006 to 2015). The accidents data are aggregated in three different main sectors defined by the typologies of roads: (1) inside the urban area, (2) motorways, (3) rural area (not motorways). The data show that the $37 \%$ of the accidents occur in the urban areas and the $55 \%$ in rural areas. The lower percentage of car accidents occur on the motorway. These data are describing a situation in which the problem is not strictly related to the speed of the cars (higher in the motorways) but that could be reasonably connected to the distribution of the territory infrastructure and services such as lighting. Figure 5b,c, respectively, present the distribution of female and male roles in the case of accidents. As clearly shown by the data presented in the two figures, males are generally the drivers involved in the accidents $(71 \%)$, whilst females have an equal distribution in the three roles.

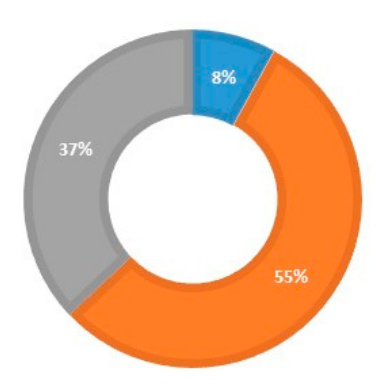

Figure 5. Cont. 


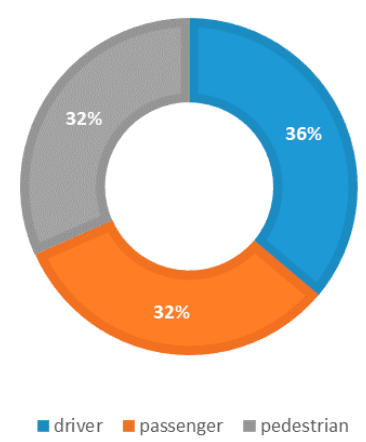

(b)

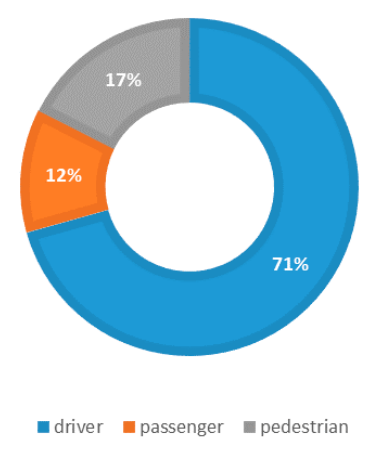

(c)

Figure 5. (a) Classification of car accidents in Europe depending on road typology (b) female distribution of the role in accidents (driver, passenger or pedestrian), (c) male distribution of the role in the accidents (driver, passenger or pedestrian).

In the city adopted as a case study in the present research, data are analyzed to correlate the lighting values to the security of the roads. The city of Milan, Italy, has thus been considered as a case study and the regional databases have been adopted as data repository about car accidents and fatalities. Statistics prove that the car accidents occurring during the night are far more dangerous than the ones occurring during the day because of the visual and behavioral problems of users that increase the task difficulties (e.g., readiness to respond to stimuli, attention, drowsiness, use of substances that alter the state of vigilance, etc.). The most recent data provided by Lombardy Region [72] show that 11,604 car accidents occurred in Milan during the year 2011, around $18 \%$ of these during the night time. Although they are a small percentage of the whole number of accidents, those that occurred during the night caused $22 \%$ of the injuries and $42 \%$ of the deaths (Figure 6). These data support the concept that darkness can aggravate the visual and behavior conditions of the drivers exposing the night activities to a high level of danger and possible critical situations.

There are many reasons that explain the statistics shown in Figure 6 and none of these should be neglected or underestimated. During the night, for example, there are more people driving under the effects of drugs or alcohol, people are tired, there are fewer police controls, etc. The inadequate lighting condition is, nevertheless, among the causes of car accidents. Therefore, considering all these issues, a correlation could be found between car accidents occurring during the night hours and incidence of car accidents. 


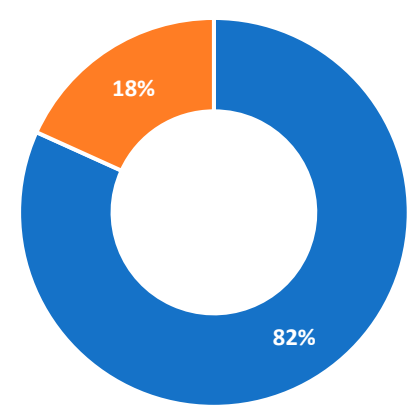

- Day . Night

(a)

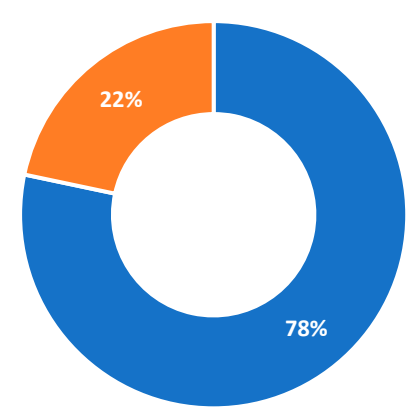

- Day - Night

(b)

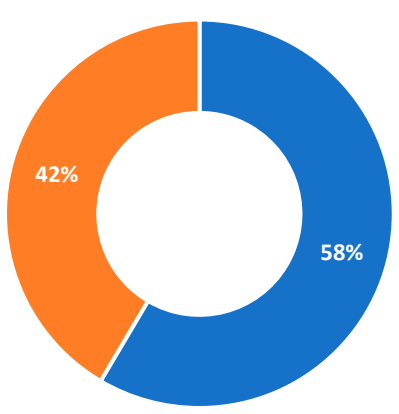

- Day $\ldots$ Night

(c)

Figure 6. (a) Car accidents in Milan, Italy during the year 2011, classified according to the time of the day of the event. (b) Injured people in car accidents in Milan during 2011, classified according to the time of the day of the accident. (c) number of fatalities during the car accidents classified according to the time of the day of the event.

\subsection{Open-Data Analysis}

Since the final aim of the research concerns the integration of the proposed method with data concerning car accidents during the night hours, the available open datasets concerning the Milan municipality (Italy) have been collected and analyzed. There are two main open datasets about car accidents in the city of Milan: the first is provided by the Lombardy Region [72] and it gives yearly data about car accidents in the city of Milan from 2000 to 2011. In this dataset, incidents are described by the means of 101 parameters regarding numbers of injuries and fatalities, time of the day when the 
incident occurred, weather condition (i.e., rainy or sunny), types and number of vehicles involved (i.e., cars, trucks, bikes and bicycles), etc.

The second open dataset [73] is provided by the municipality of Milan, it offers less detailed data about the accidents, namely only the number of incidents, injuries and fatalities, but it has monthly data from 2001 to 2017 divided by nine geographical zones numbered from 1, the city center, to 9 a peripheral zone in the north of Milan. Historical data from this dataset show that the number of accidents does not vary very much from the city center to the peripheral zone, but the number of fatalities changes significantly. In Zones 5 and 7, those with more fatalities, there are seven times the deaths registered in Zone 1, that with less fatalities as plotted in Figure 7. The number of accidents are more in Zone 8 and Zone 9 with a difference from Zone 1 of 5\% and from Zone 2 of $50 \%$.

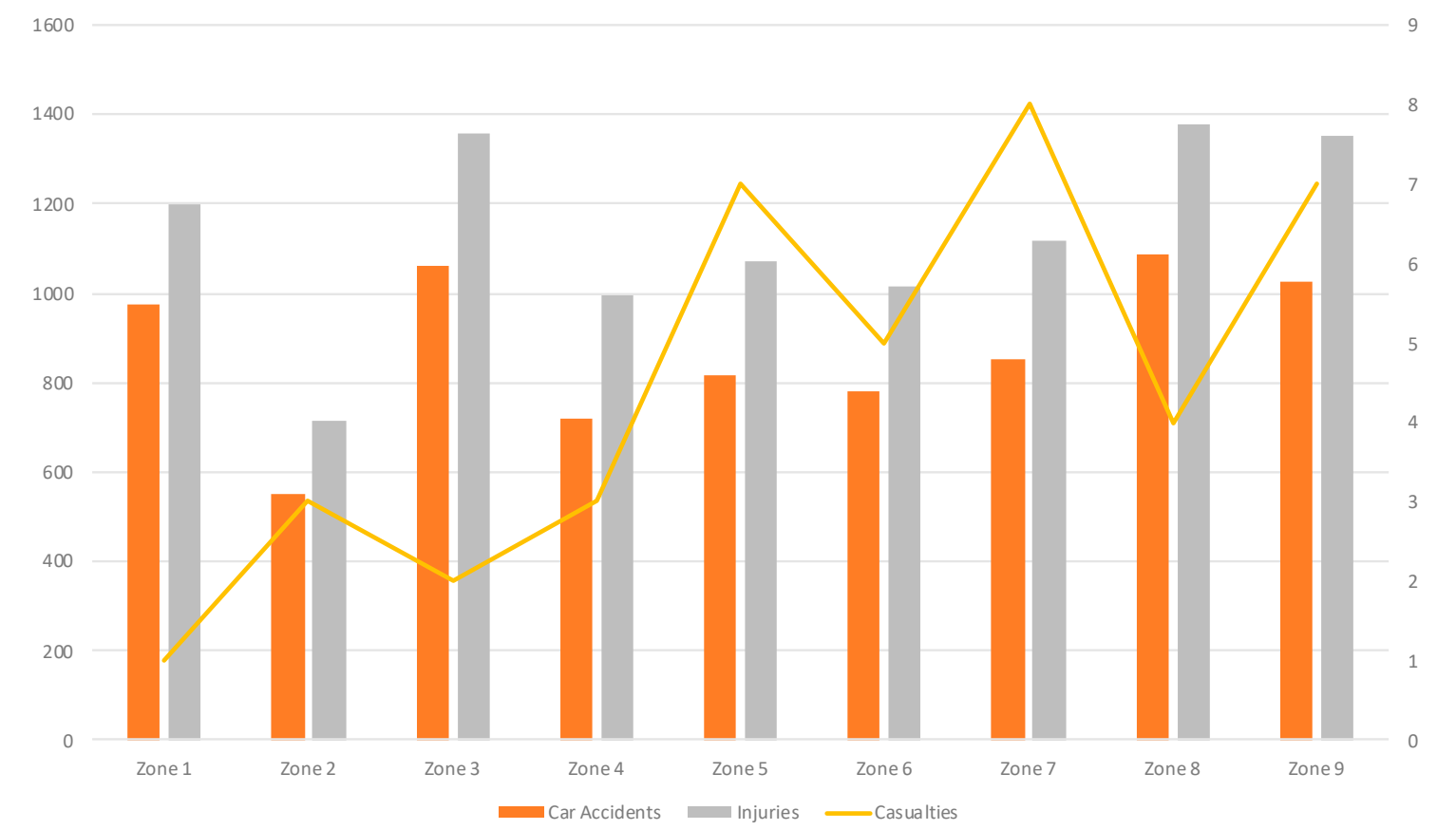

Figure 7. Total number of car accidents, injured people and fatalities in the nine zone of Milan area in 2017. The left axis represents the number of accidents and injured people while the right axis represents the number of fatalities (namely, causalities).

Noteworthy, considering the historical data about car accidents in Milan, it is possible to register a strong decrement in the time span from 2001 to 2017, as shown in Figure 8. Considering the mean of the nine zones, in 2017 there were less than half of the incidents that occurred in 2001 (from a minimum of $45 \%$ in Zone 6 to a maximum of $60 \%$ in Zone 4 and an average value of $53 \%$ of reduction). This means that security and safety campaign produced some results in the culture and control of accidents in the urban area.

The less hazardous zone, i.e., those where fewer accidents occur, do not change, however, from 2001 to 2017. They are the Zones numbered 2, 4, 5 and 6 (Figure 8). The most dangerous zone in 2001, zone 9, turned out to be the third most dangerous in 2017, exceeded in number of accidents by Zones 8 and 3 .

The same trend discussed for the number of car accidents can be observed for the number of road accidents and consequent injuries between 2001 and 2017. The average decrease in the nine zones is around $56 \%$ (minimum $48 \%$ in Zone 6 and maximum $60 \%$ in Zone 9) (Figure 9) and the zones where fewer injuries are recorded are the ones numbered 2, 4, 5 and 6 . This is not unexpected because the number of injuries is strictly correlated with the number of car accidents. 


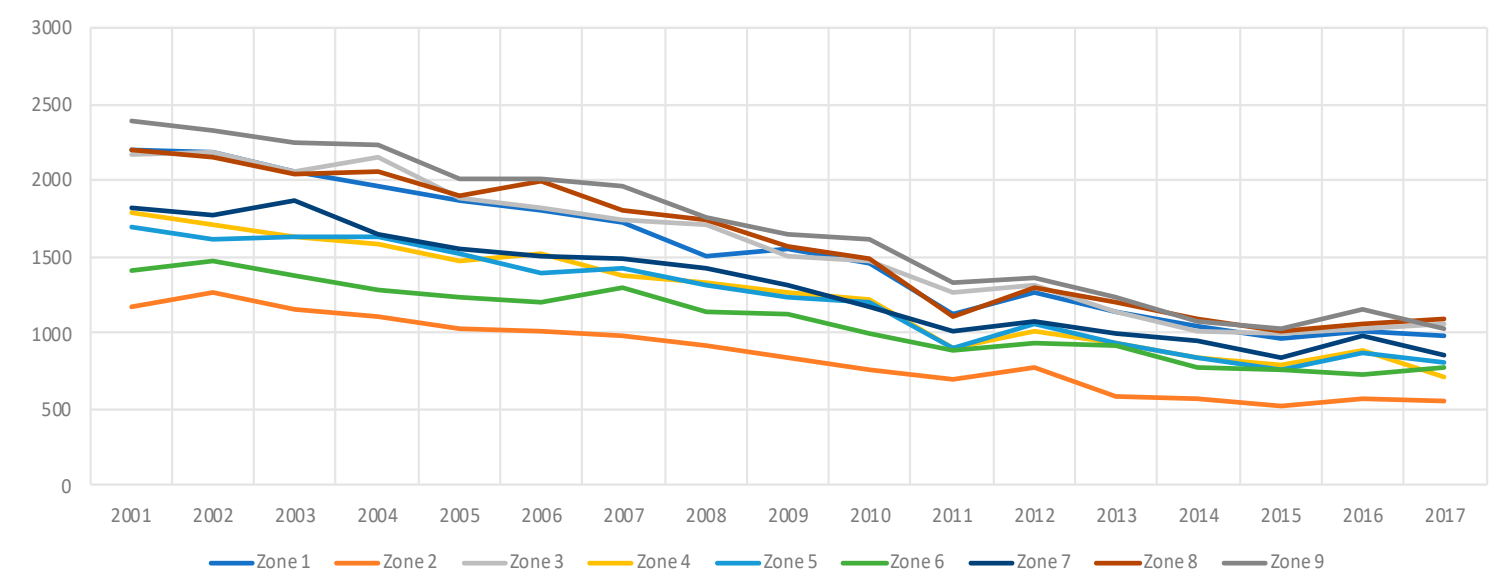

Figure 8. Car accidents in Milan according to the year and zone. The left axis represents the number of accidents.

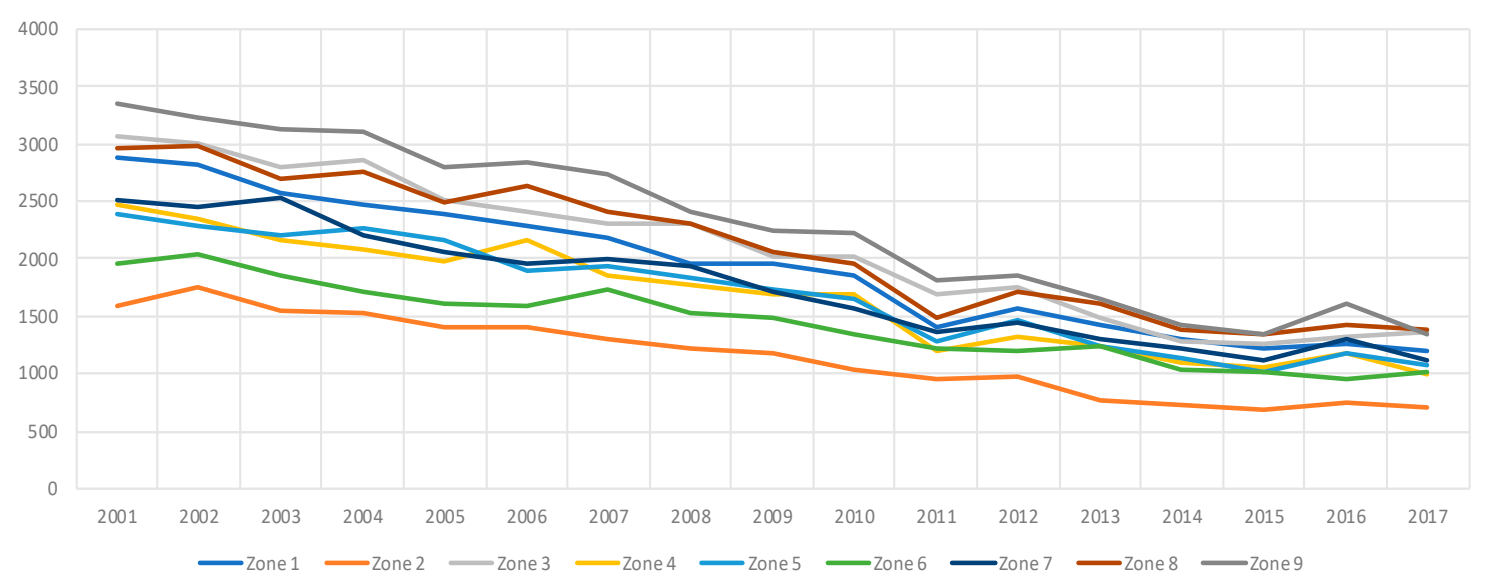

Figure 9. Number of people injured in a car accident in Milan according to the year and the zone.

The analysis of the historical data about fatalities in car accidents does not lead to similar considerations reported for injuries data. Although there is a positive trend in the number of fatalities, which goes from a total of 82 casualties in 2001 to 40 in 2017, this cannot be said about the single zone where the trend in the number of deaths seems almost a random result (Figure 10).

The maximum reduction is recorded in Zone 1 where an $80 \%$ of reduction of injuries is registered (due to also the restriction to vehicles in the city center introduced in 2011-2012, the so called area C). the minimum reduction is $13 \%$ in Zone 5. Nevertheless, the average value of reduction is $51 \%$ according to the trend of the general increase of security on the city roads.

If the focus is shifted from yearly data to monthly data (Figure 11), it can be underlined that there is a similar trend in all the nine zones in August, when in Milan there is a significant decrease of people because of the summer holidays, as the month characterized by fewer car accidents and consequently less injuries. By contrast, May and October are the months when more car accidents and injuries occur.

The average value of fatalities does not follow the same schema and, as registered for the yearly values, it is not possible to unveil a marked trend or a mathematical correlation in the data shown in Figure 11c) however Zone 9 and Zone 4 have the peak values and Zone 1 the lowest fatality value with zero in July. The monthly distribution of the accidents and injuries are absolutely regular with the following progression from the most secure to the more characterized by accident and injuries zones: Zones 2, 6, 5, 4, 7, 1, 8, 3, 9 . 


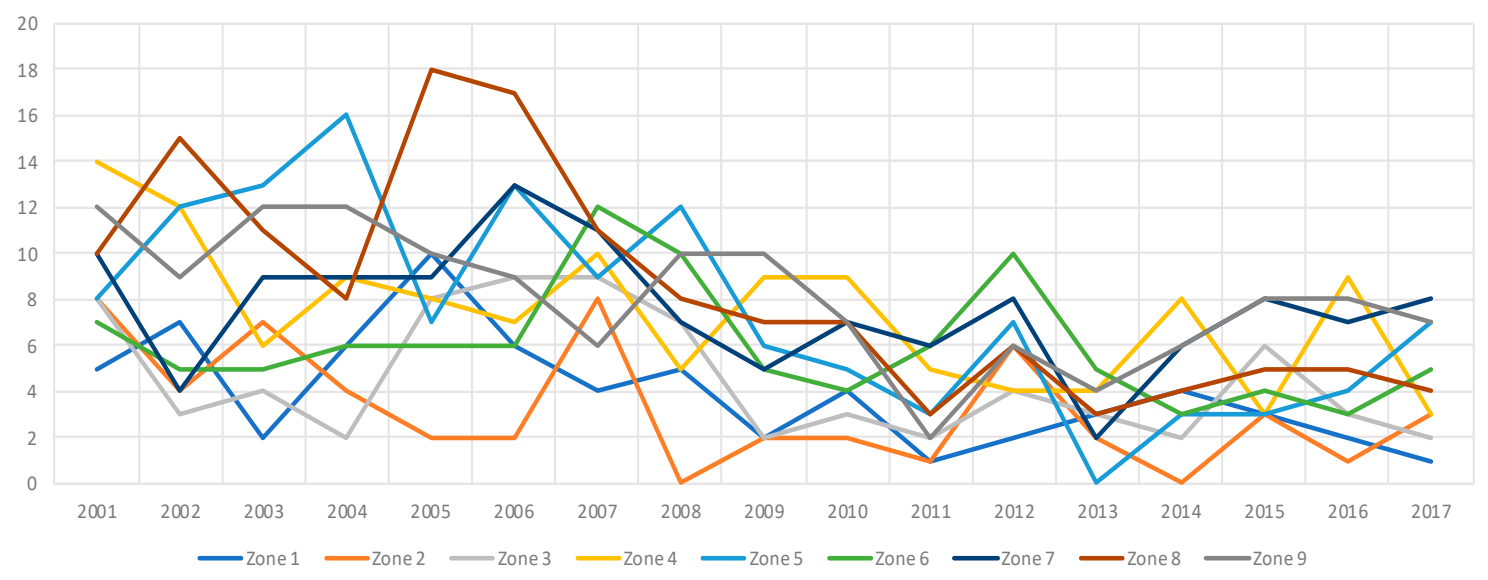

Figure 10. Number of fatalities in car accident in Milan according to year and zone.
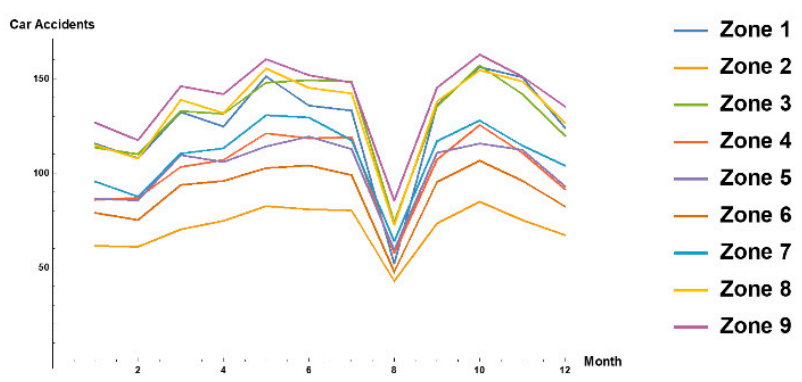

(a)
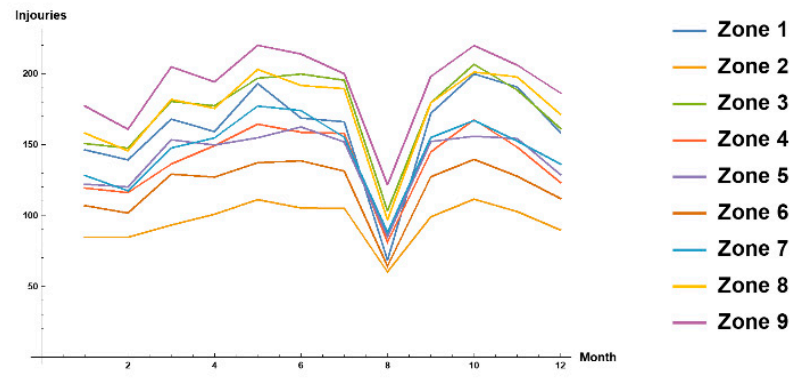

(b)
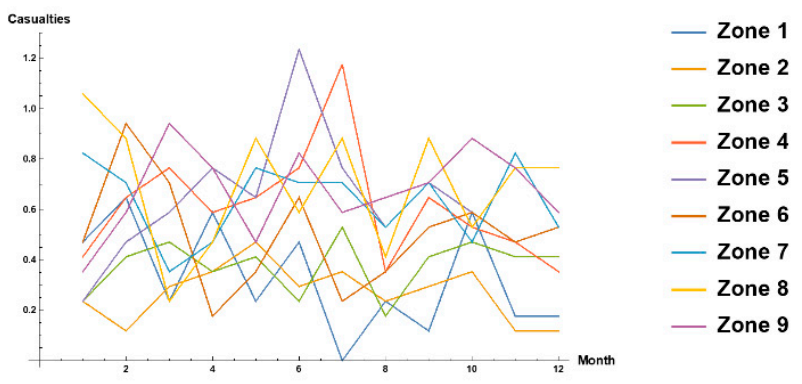

(c)

Figure 11. Average values over 16 years of the number of car accidents (a), number of injuries (b) and number of fatalities (c) in each month of the year for the nine zones in Milan. 
Historical data have been integrated into GIS maps for further analyses, and Figure 12 represents the average values of car accidents, injured people and fatalities/casualities from 2001 to 2017 in the 9 areas of Milan. As can be easily inferred, the level of aggregation of the information represented in Figure 12 is not sufficient to be employed for carrying out a reliable correlation with the collected data concerning the light intensity in some district of the city. Therefore, the integration of this data with the method presented should be considered as a next step of development of the present research. A higher level of granularity of the data is needed to perform the planned steps of the research and detailed data have already been requested by the authors to the municipality and traffic police, however, they are not available as open data.

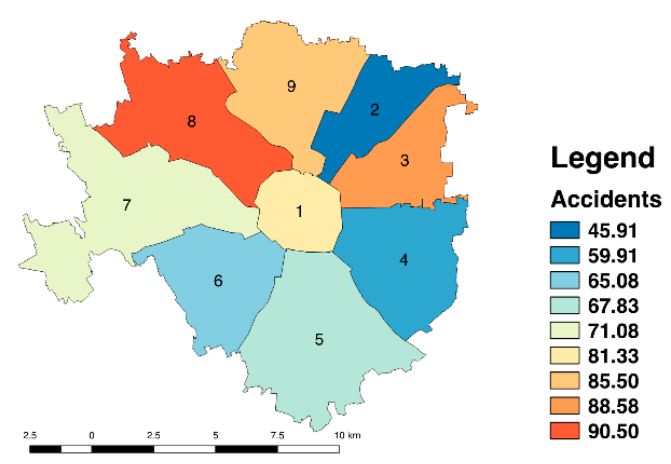

(a)

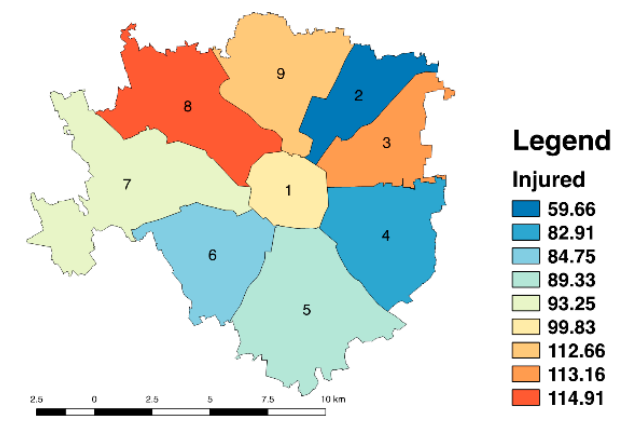

(b)

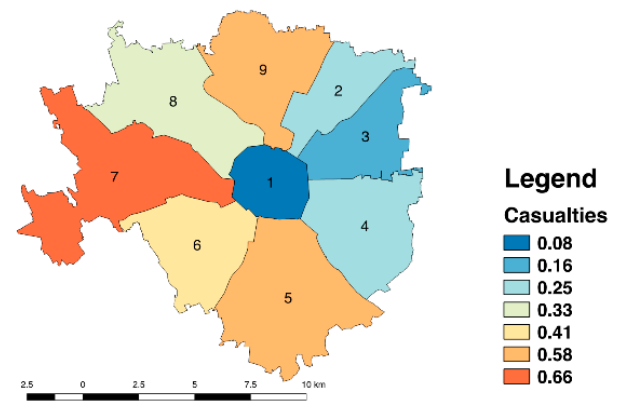

(c)

Figure 12. Representation of average car accidents (a), injured people (b) and casualties (c) in Milan zones from 2001 to 2017.

For this reason, the authors are in contact with the local police authority, which could provide access to more detailed data on car accidents. The most critical Zone 9 of Milan has been chosen and used as an experimental field of the illumination measurements, and data about car accidents with higher granularity in the same Zone 9 will be adopted, as received, as a source of data for the next step of the research to evaluate the specific correlation between urban lighting and security, following an ongoing research line which is in the process of being deepened [74]. 


\subsection{Internet of Things (IoT) Light Sensor}

The data collection and analysis method should be considered as the core part of this article. Light data collection required a light meter that can be interfaced easily with a GIS-based informative system. Given the variable nature of the urban lighting, it is important to design a measurement system able to make easy the monitoring and the storage of the data and supporting a frequent update of the data. As demonstrated in literature [75], the IoT paradigm represents the ideal solution for the interconnection of sensors to remote informative systems. The design requirement of such IoT sensors are:

(1) High range of light detection, because the device has to measure from an almost complete dark environment (the Moon's reflection is about $1 \mathrm{~lx}$ ) to a high light level under the streetlamps (the values could be near $1.000 \mathrm{~lx}$ );

(2) Geo-located measures, in order to elaborate them in the GIS to provide the data mapping at district level in the case study zone of the city of Milan;

(3) A wireless communication channel;

(4) Good portability, compactness and stability allowing the sensor to be carried around the city without significant issues (humidity problems, low weight for transportability during the inspection phases for monitoring, ability to maintain a pre-established geometric set-up, position accuracy, etc.).

Accordingly, given the aforementioned requirements, a prototype has been developed and realized using an Arduino Uno board. Besides the board itself, the main parts of the light meter are listed below:

(1) A high accuracy ambient light digital 16-bit resolution sensor (Adafruit VEML7700 Lux Sensor) characterized by a 16-bit dynamic range for ambient light detection from 0 lx to about $120 \mathrm{klx}$ to detect the difference of illuminance at the street level going from dark areas and detecting the punctual light collected under the perpendicular direction of the lamp; the resolution of the sensor is $21 x$, compatible with the application.

(2) A 56-channel GPS module with an accuracy of $2.5 \mathrm{~m}$ on the horizontal position able to localize the monitoring device in the street and possibly connect the information at a detailed location level;

(3) A micro SD Shield for an Arduino board equipped with a 64 GB micro SD card, required to store the measurement data collected from the ambient light sensor;

(4) A wireless communication channel for data transfer to a GIS-based informative system.

Figure 13 shows the different parts of the light meter assembled for some tests before using it on the experimental field. In order to fix the GPS and light sensors in a horizontal position and to make it more portable, a cardboard box has been used to introduce the monitoring device. It is noteworthy that the cardboard is white, therefore, the light reflected from the casing may affect the illuminance detection. In a similar way, the shadows cast by the operator could affect the measured luminance values. Further implementation of the experimental set-up will be tested in the following steps of the research.

\subsection{Data Collection and Geographic Information System Integration}

The stream of light data monitored from the IoT sensor are then pushed into the GIS-based informative system. The GIS stores the ID of the IoT sensors, the light measurement data, the time stamp of the measurement, and the GPS position. Potentially, more than one IoT sensor can push the data into the informative system, enabling the use of a network of IoT sensor for data mapping of the urban area. The interaction between the IoT sensor, the GIS system and the elaboration is shown in Figure 14. 


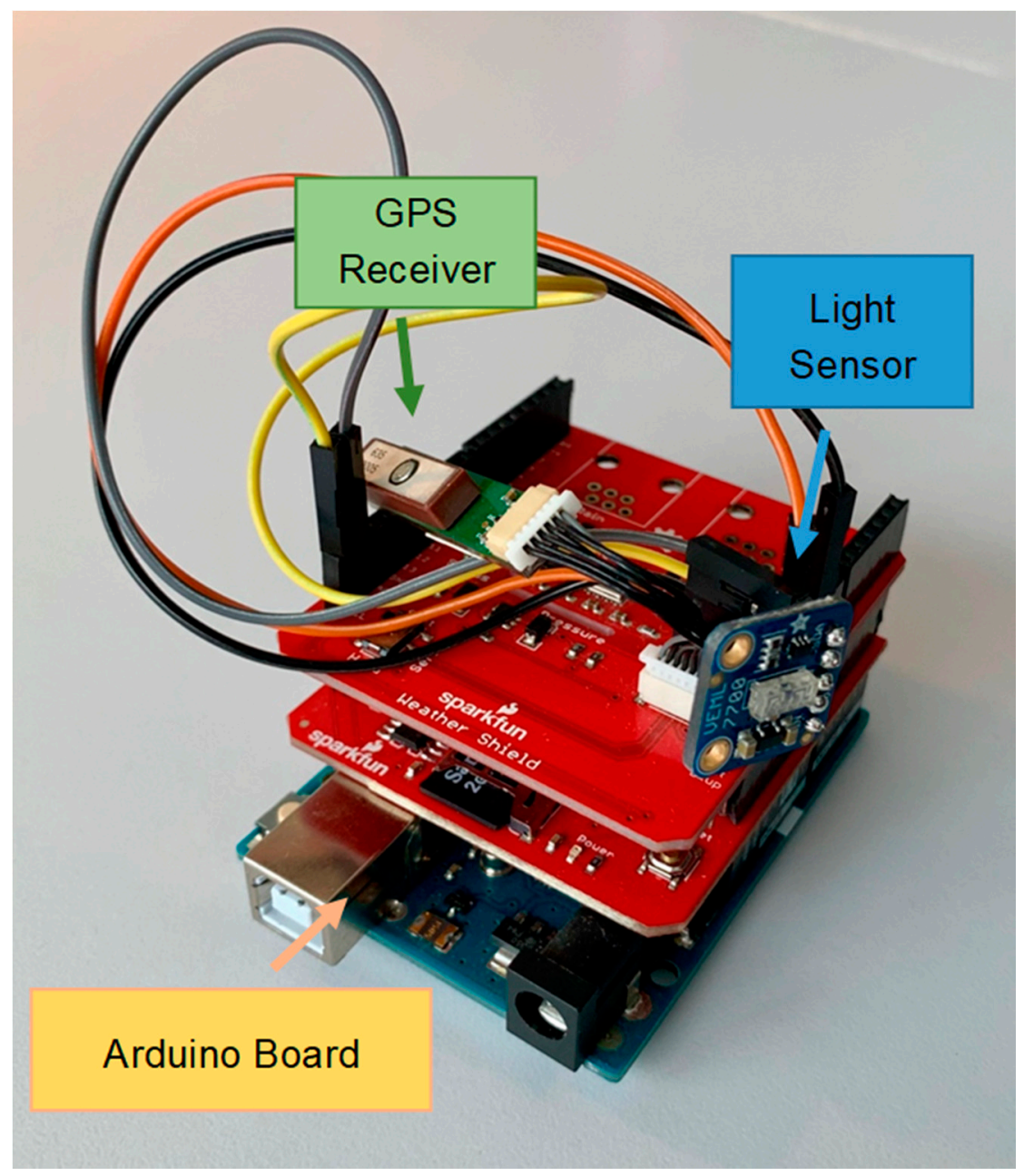

Figure 13. The light meter assembled from an Arduino Uno board without the mechanical envelope. The main components of the board are highlighted in the picture.

The IoT system has been equipped with a GPS sensor, allowing it to capture the location of each light intensity measure. Location data are collected in the WGS 84 (EPSG 3857) coordinate system. The accuracy of the GPS sensor $(2.5 \mathrm{~m})$ is enough for collecting the location of the light intensity measurement on a map. However, this accuracy could be affected by issues caused by the so-called urban canyons and issues generated by surveying areas characterized by trees with high foliage (e.g., boulevards, parks, etc.). which may determine a lower reliability in the registration of the geographic coordinates [76]. Therefore, for this research, the monitored area has been divided in a grid of $10 \mathrm{~m} \times$ $10 \mathrm{~m}$ squares $\left(20 \mathrm{~m}^{2}\right.$ area each) and an algorithm computing the arithmetical average of the detected light intensity for each square has been developed. The details of the algorithm are described in Section 5.4. The results of this computation allow us to identify the brightest and darkest areas in the urban environment, avoiding issues related to accuracy of the GPS signal. The $20 \mathrm{~m}^{2}$ grid allows us to overcome the issues related to the precision in the detection of the position of the urban elements, while correctly representing the streets and the paths in pedestrian areas. 


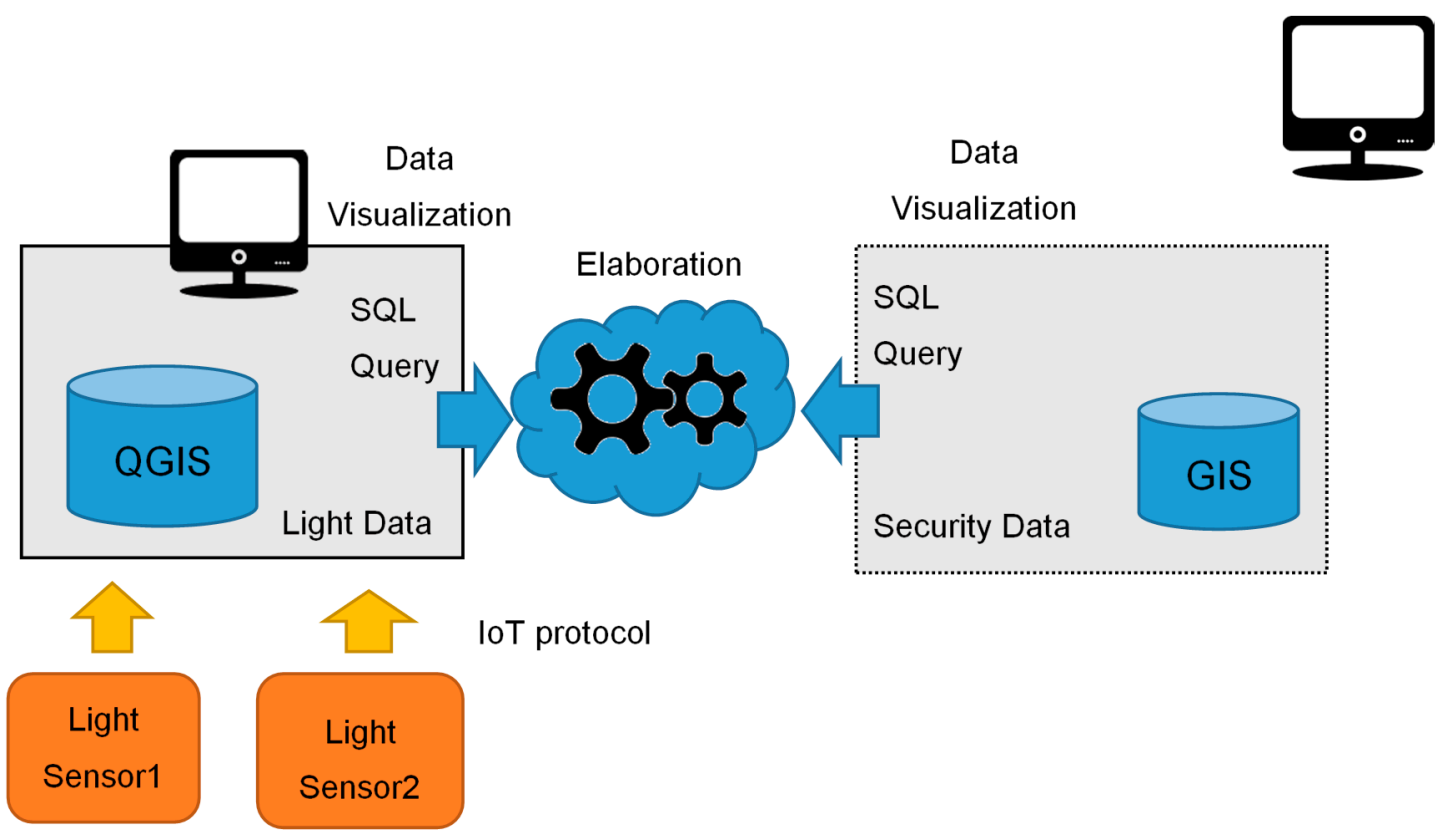

Figure 14. Interface between the Geographic Information System (GIS)-based informative system and the Internet of Things (IoT) light sensor.

\section{Case Study}

The proposed methods have been applied to a district in Zone 9 used as case study in the city of Milan, Italy. The "Città Study" neighborhood which is located around the technical university pole of the city was chosen as test bed for the implementation of the survey campaign.

An area of approximately $2000 \mathrm{~m}^{2}$ was surveyed in two nights of measurements (15 July and 23 July 2019). The area was chosen, among other reasons, because of the high average occurrence of car accidents and injured people from 2001 to 2017 as shown in Section 3.1. The surroundings of the Politecnico di Milano campus showed a concentration of degradation of the urban components and, sometimes, of social distress (Figure 15).

Moreover, the Politecnico di Milano university campus is currently undergoing a series of refurbishments and regeneration interventions, involving the retrofit of some existing buildings, the construction of new ones and the renovation of public open spaces that will lead to a new configuration of the area. Thus, an analysis of the current light quality in the area will be useful data for the designers involved in the renovation project.

As described in the previous section, the IoT sensor has been designed in order to optimize its compactness and portability. Each of the IoT sensors can be mounted on a mobile mechanical structure for tracking the level of luminosity on the road. During the case study, the sensor has been mounted on an odometer to allow easy monitoring. An operator performed the recognition on the neighborhood area involved in the case study using the odometer equipped with the light sensor. A single IoT sensor was used to collect all data during the two nights of the duration of the experiment. Each measurement campaign generated 2000 sampled data. It should be highlighted that the IoT sensor can be mounted on any mobile mechanical structure, such as an unmanned aerial vehicle (UAV) or unmanned ground vehicle (UGV), to create an autonomous measuring system for the mapping of an entire city. Such an approach has the great advantage that the IoT sensors are monitoring a predefined and well-known path. Notwithstanding such benefits, the integration of the light sensors on autonomous monitoring system is out of the scope of the current research work and it will be investigated in future research work. 


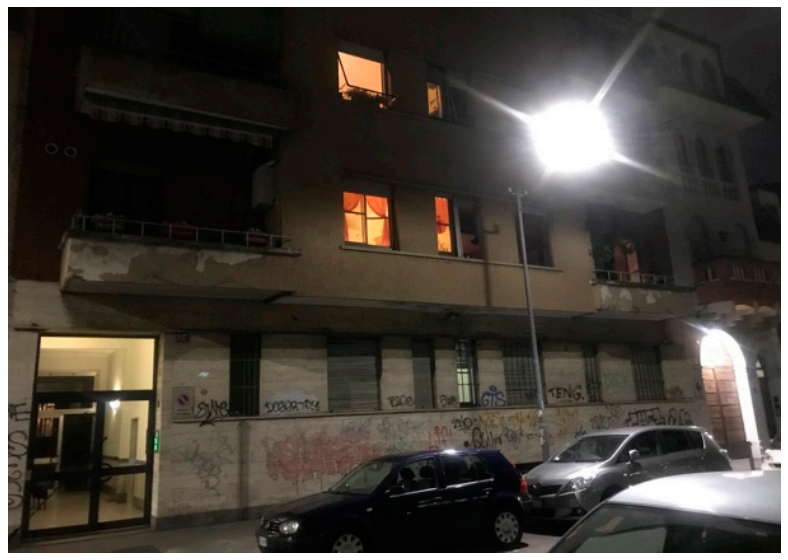

(a)

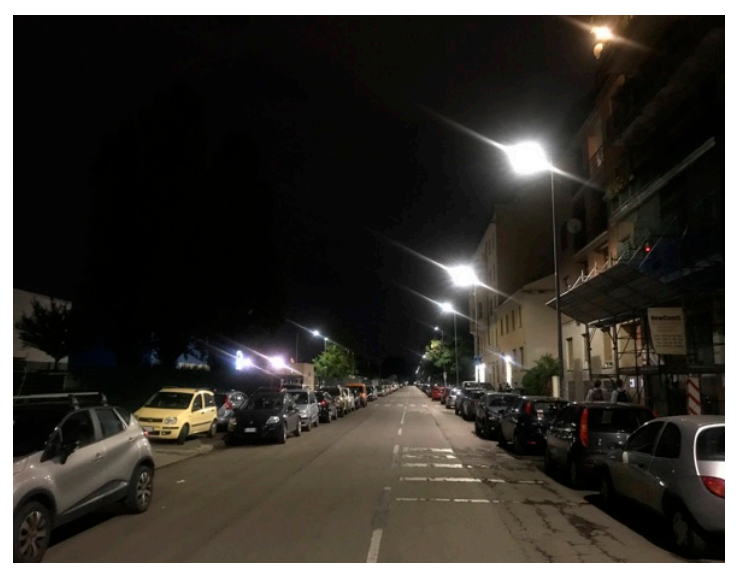

(b)

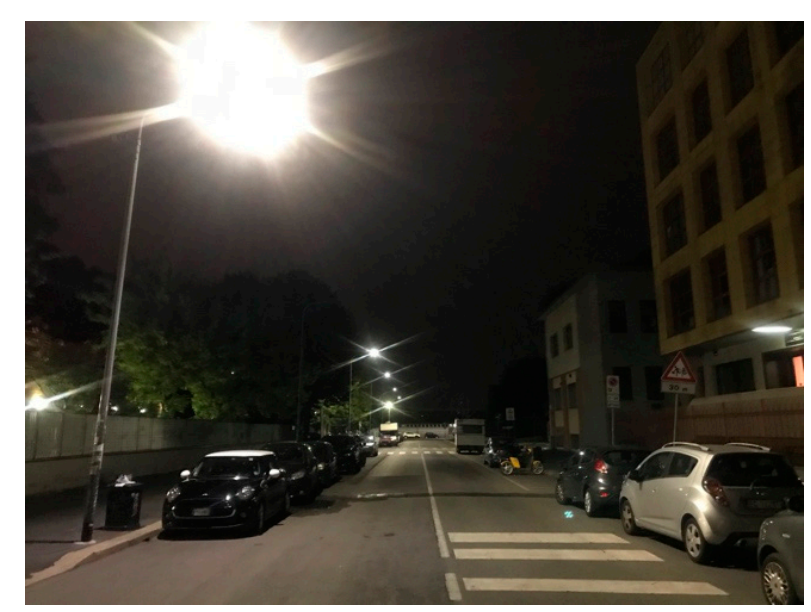

(c)

Figure 15. Cont. 


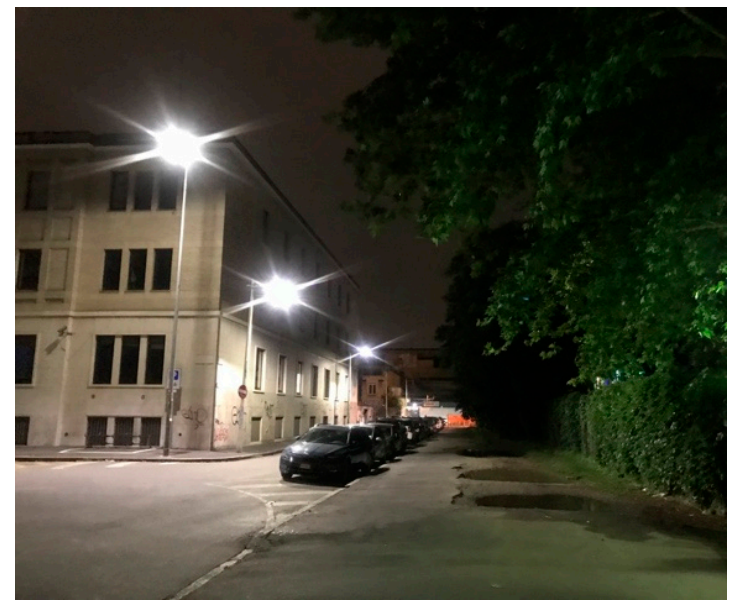

(d)

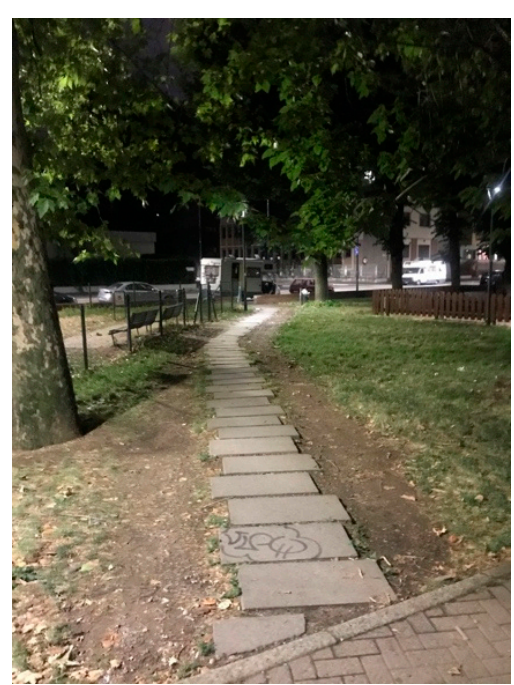

(e)

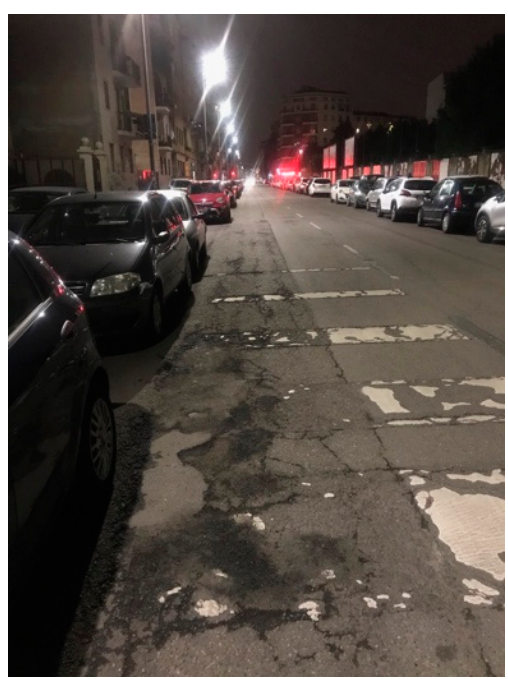

(f)

Figure 15. Cont. 


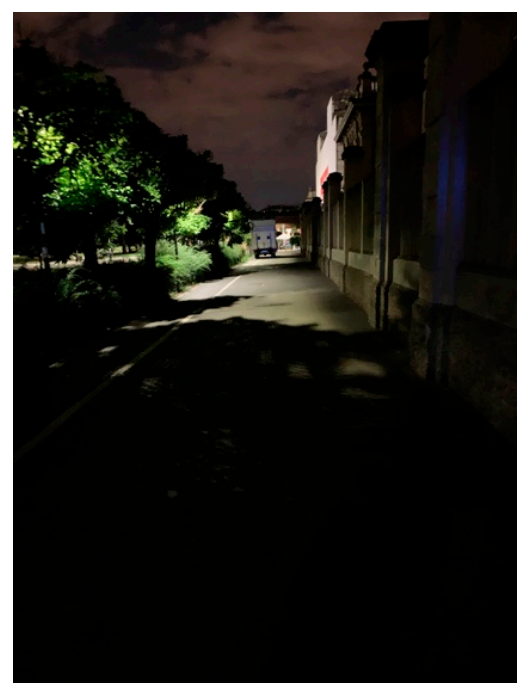

$(\mathrm{g})$

Figure 15. Pictures of critical areas (a-g) where building and street degradation, lack of lighting and perceived unsecurity in the neighborhood were detected and in which the proposed approach was tested.

\section{Results}

\subsection{Degradation Assessment}

The measurement campaign allowed to collect information about the situation of the district as first as description of the degradation (e.g., physical degradation of buildings and roads, social distress of people mobile temporarily living solutions such as camper vans, use of the city parks as hygienic support services for temporary living, discontinuity of illumination of the district ranging from illumination to complete darkness) spots in the area.

The district has some hotspots such as pubs and restaurants with a low concentration, whilst the main vocation of the zone is residential. Community services of the district are a sports ground and some small urban parks. The measurements have been validated by double checking the collected values in the two monitoring dates.

The social situation has been varied in the two dates and the mobile houses changed their positions near to the park to a non-monitored location. During the measurement campaign it was possible to verify the neighborhood conditions where buildings degradation due to lack of maintenance and cleaning procedures (Figure 15a,b), road problems of the pavement and of the horizontal signage for pedestrians (Figure 15b,d,f), asymmetrical lighting and temporary mobile housing in camper vans (Figure 15c-e) and excessively darkness for people safety and street security (Figure 15g) have been detected.

\subsection{Urban Lighting Assessement}

The European standard EN 13201-3 [77] gives rules on the points where lighting measurements should be taken. Since the purpose of survey was not the measurement of the photometric quality of the lighting installations, during the data collection the grids mandated by the European standard were not used. Points located in the shade of objects (i.e., trees) that should be avoided according to the standards were, in fact, preferred measurement locations because the step passage from dark shadow to shiny lighting can affect driving performance.

More than 2000 points distributed along almost $6.5 \mathrm{~km}$ were collected in the first campaign. Half of them, reported in Figure 16a, were below 32 lx and more than $52 \%$ of the points were below 50 lx, which are the light levels of public areas with dark surroundings according to the NOAO (National 
Optical Astronomy Observatory), national center for ground-based night-time astronomy in the United States [78]. Moreover, it is worth noting that $12.5 \%$ of the points are above $500 \mathrm{~lx}$ and three of them exceed $2500 \mathrm{~lx}$. These points where recorded under the direct light of lighting systems of private parking lot thus they are not significant in the number of records and they are not describing specific areas with high illuminance level but points of discontinuity in the average distribution. Thus, such values can be disregarded in the following analysis.

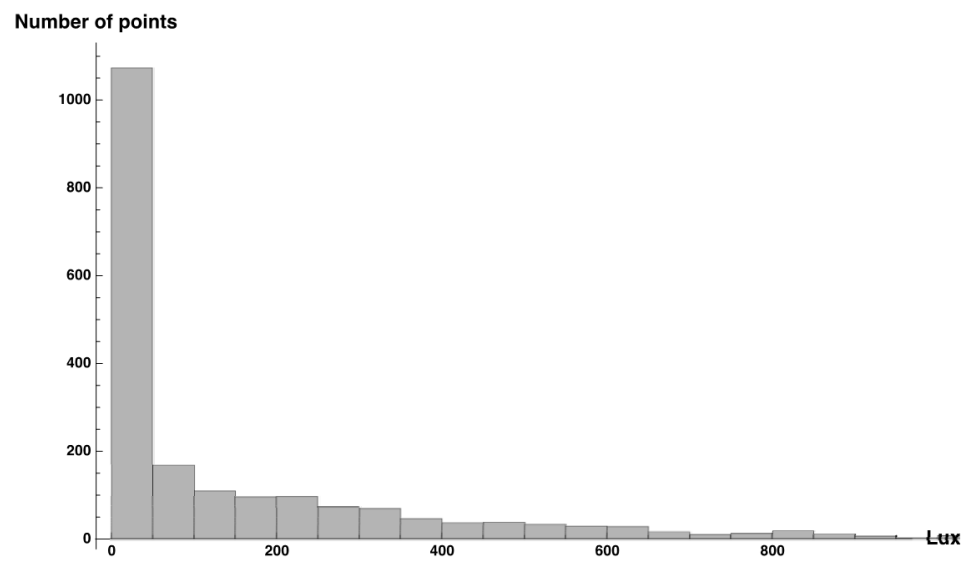

(a)

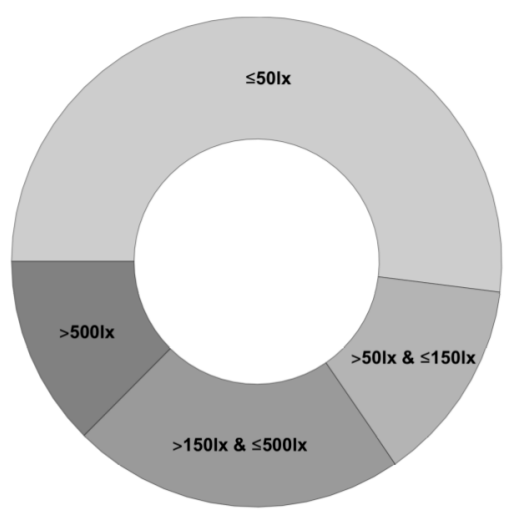

(b)

Figure 16. (a) Histogram of the distribution of lux level of the measurement points; (b) classification of the detected illuminance according to NOAO thresholds.

A further parameter that could be added in the lighting evaluation could be the uniformity ratio given by the average illuminance and the minimum illuminance $\left(E_{a v} / E_{\min }\right)$ that has defined values ranging from 3 (for expressway to 6 for local roads) and it is a crucial value for visual comfort and adaptability in the scotopic vision of the human eye. The problems that could be related to the luminance values are:

(1) The illuminance must be sufficiently high in relation to the dimensions of the object, to the contrasts, to the time of perception and to the age of the subject;

(2) The luminance of the area immediately adjacent to the visual task must not be higher than the visual task itself;

(3) The contrast between the immediate background of the visual task and the environment must not be accented and the transition should be gradual;

(4) The most appropriate solutions have been taken to avoid glare. 
It is useful to remember that illuminance describes the measurement of the amount of light falling onto and illuminating a given surface area. Illuminance is also correlated with how humans perceive the brightness of an illuminated area.

As a result, most people use the terms illuminance and brightness interchangeably; however, this can lead to misunderstanding, as brightness is also used to define luminance. Illuminance refers to a specific kind of light measurement, while brightness refers to the visual perceptions and physiological sensations of light.

Luminance describes the measurement of the amount of light emitting, passing through or reflected from a particular surface from a solid angle. It also designates how much luminous power can be perceived by the human eye. This means that luminance indicates the brightness of light emitted or reflected from a surface (Figure 17).
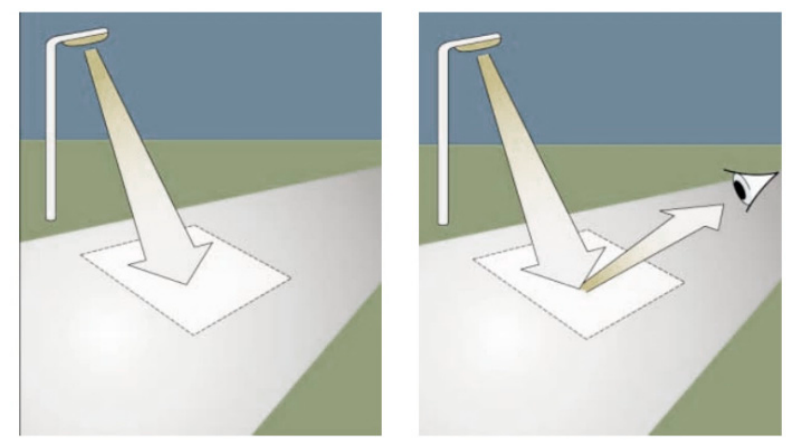

Figure 17. Definition and differences between (a) illuminance in lux $\left(\mathrm{lm} / \mathrm{m}^{2}\right)$ and (b) luminance in $\mathrm{cd} / \mathrm{m}^{2}\left(\mathrm{~lm} / \mathrm{sr} \times \mathrm{m}^{2}\right)$.

\subsection{Urban Lighting and Safety Perception}

Current LED road lighting has a poor longitudinal luminance uniformity which is described as a "zebra effect" [79] that can easily cause eye fatigue and the reduction of safe driving (Figure 18).

To solve this problem, some researchers adopted specific illuminance distribution curves to accomplish a certain illuminance and luminance uniformity by adjusting the curve parameters [80]. But these methods cannot achieve ideal illuminance and luminance uniformity simultaneously and are only appropriate for specific roads. The main aspects affecting the visual perception in road driving and thus that are relevant for security and safety for drivers are average road surface luminance, overall and longitudinal luminance uniformity, glare control, and color rendering index [81]. However, the pedestrian perception of security is also a combination of environmental and social degradation elements and signs as well as the aforementioned lighting conditions of the road and sidewalks.

\subsection{Urban Illuminance Mapping}

Points have been imported and georeferenced in a GIS (QGIS) and have been used for the development of the data analysis algorithm. For this purpose, a polygon grid $10 \mathrm{~m} \times 10 \mathrm{~m}$ has been developed considering an extension equal to the maximum extent of the coordinated points representing the measured light intensity. The first insight of where the measurement characterized by higher light intensity are localized in the selected area is shown in Figure 19. Data have been categorized according to 6 classes of light intensity (shown in the legend of Figure 19), considering equal intervals. The last class shows values characterized by a very high illuminance values despite it is composed by only 2 values, recorded under direct lights (a private parking lot and the very bright sign of a commercial activity). 


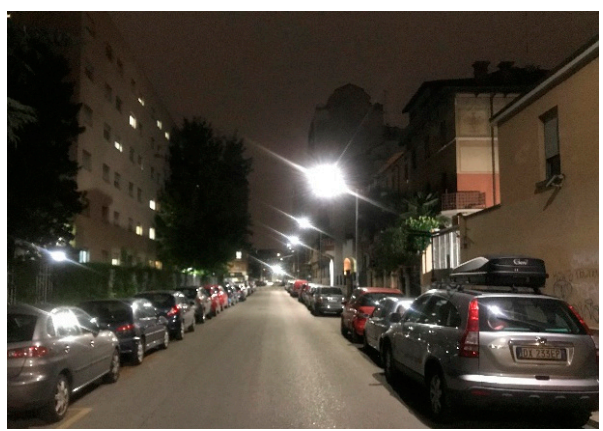

(a)

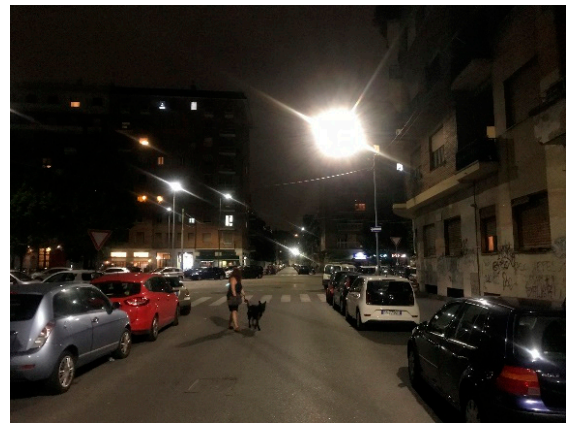

(b)

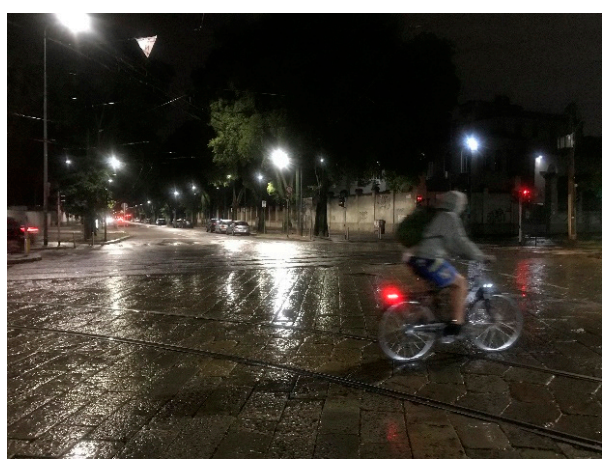

(c)

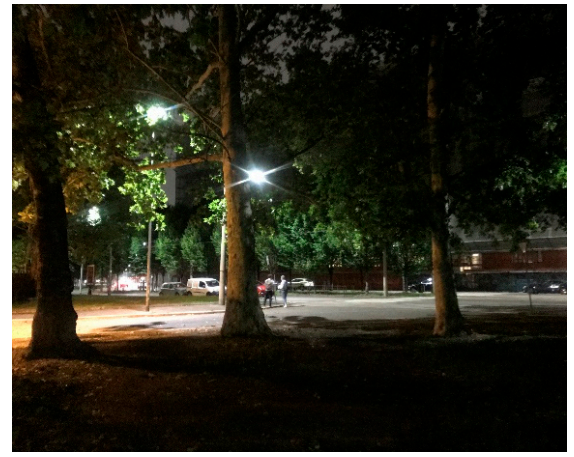

(d)

Figure 18. (a) "Zebra effect" on the pavement (horizontal bands with different lighting levels); (b) safety perception of a pedestrian related to lighting levels and degradation signs on the built environment (lack of maintenance and vandalism on the facades); (c) difference of pavements in the city and increased danger for bikes and motorbikes when raining; (d) shading of the urban lighting provided by the trees distributed in parking areas and urban residual parks decreasing visual capability and safety perception for pedestrians. 
It is possible to note an unevenness of distribution of the illuminance values: the most illuminated locations are those where interesting activities are spotted (the university main fronts, some leisure locations such as pub and restaurants and the crossing of some bigger urban streets). By contrast, a large part of the measurements fall in the low level of illumination range, between 0 and $539 \mathrm{~lx}$. Thus, unequally spaced intervals are considered (shown in the legend of Figure 20) in order to better analyze the visual effect of brightness and darkness that can be perceived by citizens. The raw light measurement data are spatially merged in a grid of $10 \mathrm{~m} \times 10 \mathrm{~m}$ squares (an area of $20 \mathrm{~m}^{2}$ each), in order to reduce the number of points to analyze on the GIS. In addition, as discussed in the previous section, the measurement set-up is affected by a variability contribution which depend by the mechanical system used to support light sensors during the measurement campaign through the city. Although such variability is well below the accuracy required by the analysis performed in this paper, the light data in each square of the grid are arithmetically averaged, to reduce the measurement variability. An SQL (structured query language) script allows to compute the arithmetical average light intensity, maximum and minimum light intensity values and the number of points in each of $10 \mathrm{~m} \times 10 \mathrm{~m}$ polygonal grid. Figure 20 represents the outcomes of this data analysis. The visualization allows us to identify areas in the test bed neighborhood with different illuminance levels. The lower ranges of luminosity correspond to locations where it could be useful to intensify the illumination level and to provide new systems to increase safety and security in a developing area of the city subjected to regeneration processes.

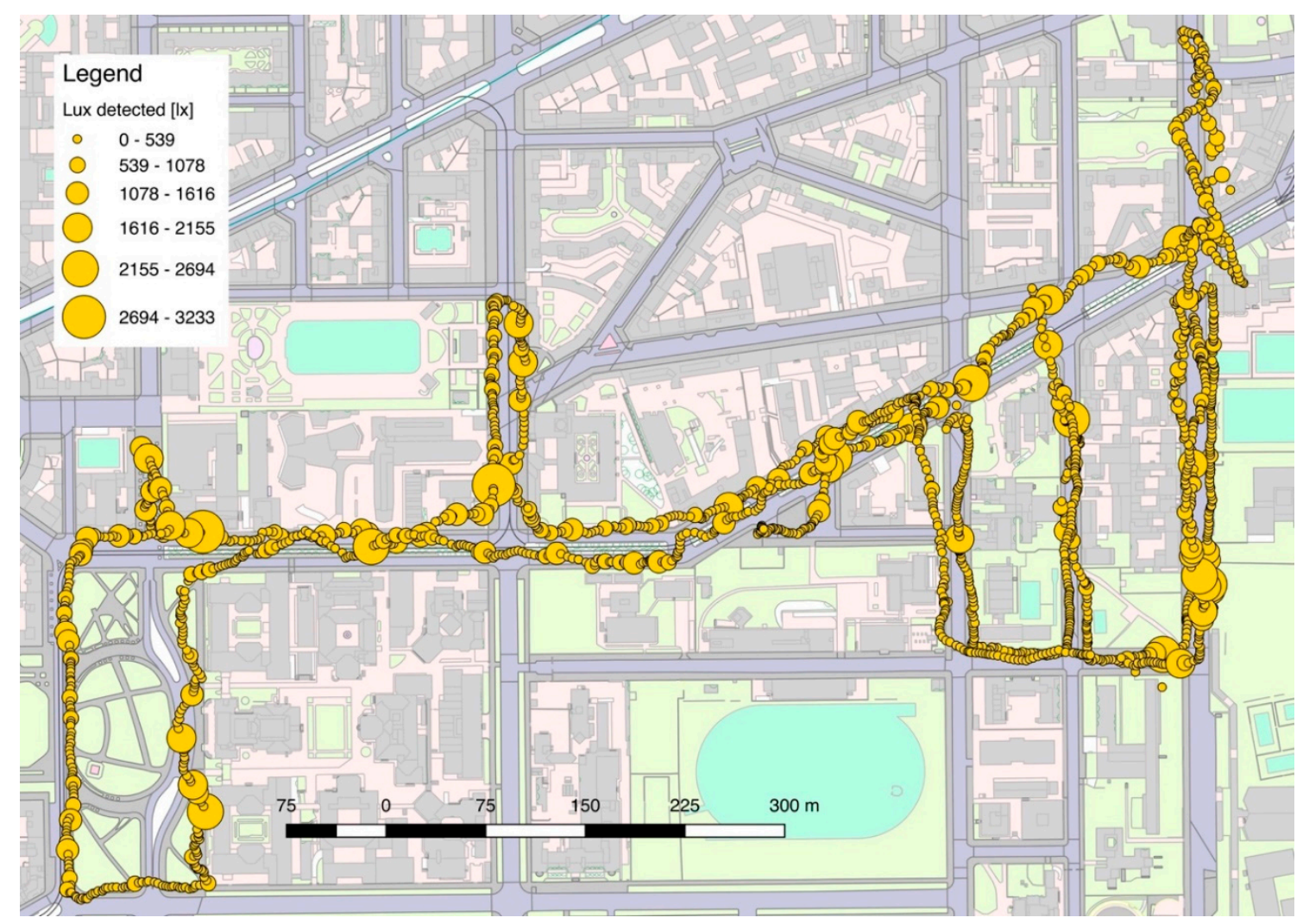

Figure 19. Results of the measurement campaign. The dimension of the circles is proportional to light intensity. Six light intervals (equally spaced) are considered in the figure. 


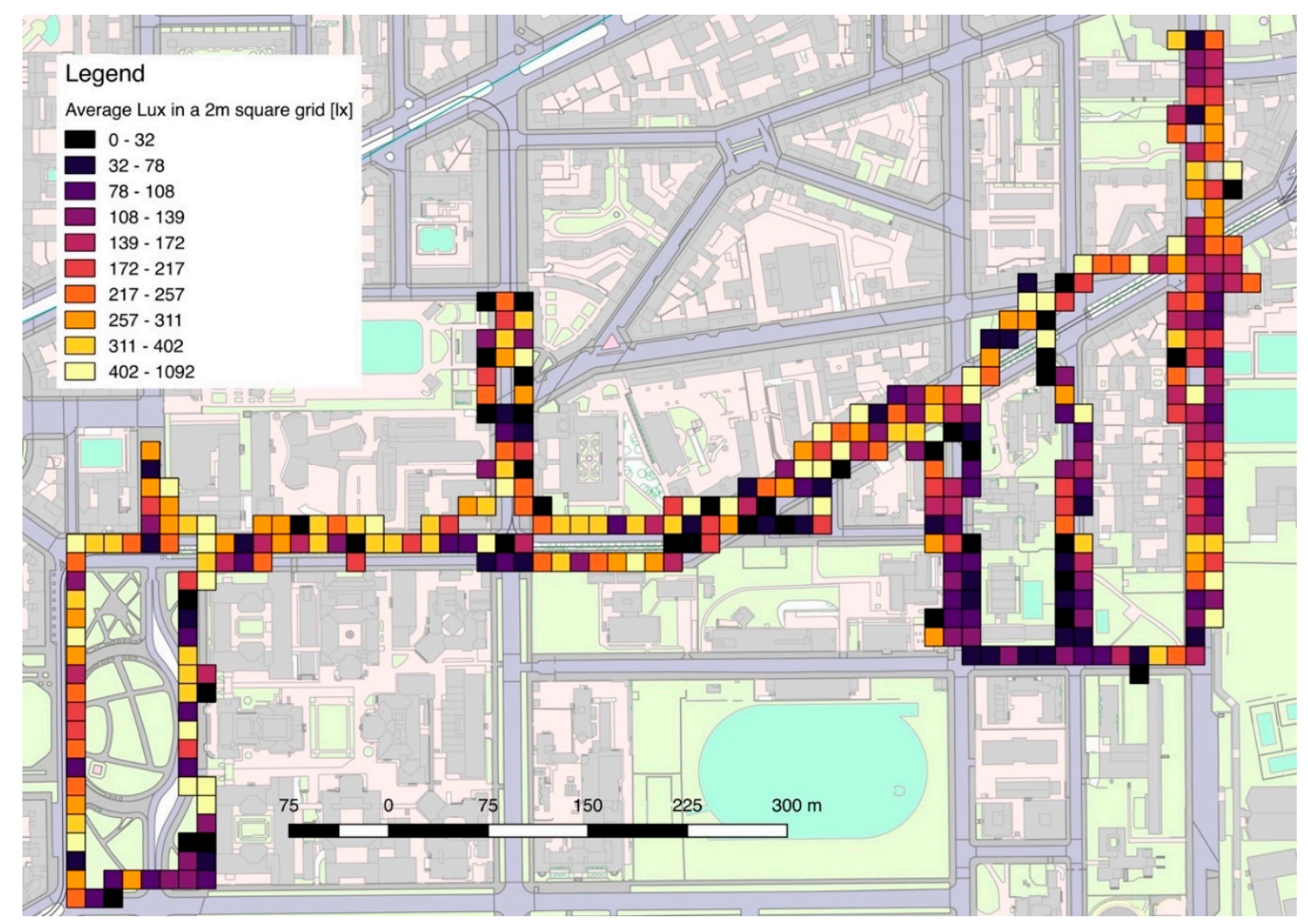

Figure 20. Measured illuminance (average lux), aggregated within a grid of squares of $10 \mathrm{~m} \times 10 \mathrm{~m}$ each.

\section{Discussion}

Several metrics can be used to infer quantitatively the perceived level of security of citizens in the different area of a city: crimes per area, road accidents, personal assault, and many more. There is evidence from the literature that such metrics are directly affected by the quality of street lights: poor lighting is correlated with an increase of the perceived level of insecurity. However, it is not possible to increase indiscriminately the level of lighting in any area of the city, both for economical as well as environmental reasons (energy consumption and light pollution). Thus, it is important to have an accurate map of the quality of lighting in the different areas of the city. Such data should be correlated with other metrics to identify the area which requires an improvement in quality light. Current research work focuses on a methodology able to generate an accurate mapping of lighting quality in urban area. These data are correlated with road accidents information to demonstrate the feasibility of the proposed approach.

The survey campaign for quality light monitoring has been carried out in the most accurate way possible, despite some drawbacks that can be highlighted. Due to the experimental nature of the proposed procedure, the orthogonality of the sensor to the ground could be improved, ensuring that the detection tools are always horizontal. Moreover, the variation of height from the ground could have been affected for the same reasons, despite always carefully remained within a reasonable range. These issues may cause a bias in the detection of the light intensity data. However, the final evaluations are carried out on average values computed on the $10 \mathrm{~m} \times 10 \mathrm{~m}$ grid, therefore the single values are not considered, but in intermediate steps of the proposed approach.

A further improvement of the research concerns the accuracy in the detection of the position of the sensor when recording the light intensity data. For the case study presented in this article a grid $10 \mathrm{~m} \times 10 \mathrm{~m}$ has been adopted. This allows us to represent the light intensity along the streets and the open spaces of the neighborhood, although not providing enough detail needed to represent and analyses specific technical units of the urban environment (e.g., carriageway, pavement, parking lots 
etc.). This aspect will be addressed and some research insights will be carried out in order to be able to reach a finer granularity in the analysis and visualization of the geolocated data. An oversampling of the data from ambient length sensors could be a possible solution.

The proposed method has been developed following the guidelines of the EN 13201-4 [82], in particular, the following steps of the research on the orthogonality of the light detecting sensor will be improved as well as the continuity in the height at which the measures are taken. However, the standard should be used when the purpose of characterizing lighting installations considers the photometric quality parameters, an objective that is not completely within the scope of this research, oriented towards the assessment of the security of urban space related to the light intensity.

Another issue that may have affected the detection of the light data concerns the setup of the Arduino equipped with the sensors. The breadboard has been inserted in a white paperboard box. The light reflecting on the paperboard may have affected the detection of the light intensity, decreasing the accuracy of the values. This issue could be overcome adopting an improved installation setup, or simply employing a black paperboard box.

\section{Conclusions}

The planning of the renovations of street light infrastructures in urban areas should take into consideration several parameters. The level of light in urban areas cannot be arbitrarily high due to economical as well as environmental (energy consumption and light pollution) reasons. At the same time, the level, and the quality, of light is strictly correlated with the perceived level of security of the citizen. The research work proposed a methodology for the planning of light renovations based on the correlation of GIS data from different sources. The map of the quality of the street light in the different urban areas is correlated with other GIS data, which can be considered quantitative indexes of the perceived level of security. In particular, in the current research the number and geographical distribution of road accidents was considered an example of metrics to be used to validate the proposed approach. The publicly available road accident data of the Milan area has been analyzed. It is possible to underline as a further step of the research that it will be enriched with the road accidents data that will allow a significant comparison with drivers' difficulties in the tested area of the city located in Zone 9 which is the most subject to car accidents. The idea is to extend the indicators (the hard KPI) with the crowdsourcing data about perceived safety from the citizens (soft KPI) which can compose a structured proposal for implementing the lighting systems of the neighborhoods and provide the municipality an effective strategic plan to develop the renovated university campus area. It is worth underlining that the use of only the measures suggested by the EN 13201-4 are not enough to assess urban security because lighting not directly related to roads are needed for this purpose to include the pedestrians' perception under the different segments of the city areas (including green areas and urban parks). The urban lighting data mapping could drive informed decisions on increasing the public lighting infrastructure since public light can improve social security and perception of physical degradation, increasing community pride and participation to the social good and urban care. The increase of lighting points could be developed with new smart systems able to use renewable energies and dimmer light related to the presence sensors avoiding a waste of energy and recreating a customized living lighting environment which could envision an augmented user experience and environmental and economic sustainability levels. The proposed GIS integration is a powerful tool for urban regeneration, driving urban policies at the local scale with an efficient granularity of intervention that could increase the quality of the urban environment.

Author Contributions: Conceptualization, L.C.T. and F.R.C.; methodology L.C.T., F.R.C, S.R.; software, F.R.C, N.M., P.B.; validation, S.R., F.R.C. and P.B.; formal analysis, N.M.; investigation, F.R.C., N.M., L.C.T.; resources, F.R.C.; data curation, N.M., F.R.C; writing-original draft preparation, L.C.T, N.M.; writing—review and editing, S.R., L.C.T.; visualization, F.R.C., N.M.; supervision, L.C.T., F.R.C, A.L.C.C.; project administration, L.C.T; funding acquisition, F.R.C. All authors have read and agreed to the published version of the manuscript.

Funding: This research received no external funding. 
Acknowledgments: The authors would like to thank Marco Pasetti for the useful discussion about the monitoring setup in the planning phase.

Conflicts of Interest: The authors declare no conflict of interest.

\section{References}

1. UNFPA-United Nations Population Fund. State of World Population 2018: The Power of Choice; UNFPA: New York, NY, USA, 2018; p. 156. ISBN 978-1-61800-032-3.

2. UNFPA-United Nations Population Fund. State of World Population 2007: Unleashing the Potential of Urban Growth; UNFPA: New York, NY, USA, 2007; p. 108. ISBN 978-0-89714-807-8.

3. IPCC. Working Group III (Mitigation)-Chapter 12. Human Settlements, Infrastructure and Spatial Planning. Available online: https:/www.ipcc.ch/site/assets/uploads/2018/02/ipcc_wg3_ar5_chapter12.pdf (accessed on 19 March 2020).

4. UNFPA-United Nation Population Fund. Available online: http://www.unfpa.org/pds/urbanization.htm (accessed on 19 March 2020).

5. Hamidi, S.; Ewing, R.; Tatalovich, Z.; Grace, J.B.; Berrigan, D. Associations between Urban Sprawl and Life Expectancy in the United States. Int. J. Environ. Res. Public Health 2018, 15, 861. [CrossRef]

6. Rodwin, V.G.; Gusmano, M.K. Growing Older in World Cities: New York, London, Paris, and Tokyo; Vanderbilt University Press: Nashville, Tennessee, 2006; ISBN 0-8265-1490-1.

7. STAP The Scientific and Technical Advisory Panel of the Global Environment Facility. Sustainable Urbanization Policy Brief: Proliferation of Urban Centres, their Impact on the World's Environment and the Potential Role of the GEF; Report to the 5th GEF Assembly, México May 2014'; Global Environment Facility: Washington, DC, USA, 2014.

8. C40 Cities Climate Leadership Group. Available online: http://c40.org (accessed on 20 March 2020).

9. The Global Commission on the Economy and Climate. The New Climate Economy Report. 2014, Better Growth Better Climate, Charting a New Path or Low Carbon Growth and Safer Climate; New Climate Economy (NCE): Washington, US, USA, 2014.

10. Rizzi, M.; Depari, A.; Ferrari, P.; Flammini, A.; Rinaldi, S.; Sisinni, E. Synchronization Uncertainty Versus Power Efficiency in LoRaWAN Networks. IEEE Trans. Instrum. Meas. 2019, 68, 1101-1111. [CrossRef]

11. Rinaldi, S.; Bonafini, F.; Ferrari, P.; Flammini, A.; Sisinni, E.; Cara, D.D.; Panzavecchia, N.; Tine, G.; Cataliotti, A.; Cosentino, V.; et al. Characterization of IP-Based communication for smart grid using software-defined networking. IEEE Trans. Instrum. Meas. 2018, 67, 2410-2419. [CrossRef]

12. Pasetti, M.; Rinaldi, S.; Manerba, D. A virtual power plant architecture for the demand-side management of smart prosumers. Appl. Sci. 2018, 8, 432. [CrossRef]

13. Rinaldi, S.; Della Giustina, D.; Ferrari, P.; Flammini, A. Distributed monitoring system for voltage dip classification over distribution grid. Sustain. Energy Grids Netw. 2016, 6, 70-80. [CrossRef]

14. Shlomo, A. Making Room for a Planet of Cities, Policy Focus Report; Lincoln Institute of Land Policy: Cambridge, MA, USA, 2011; ISBN 978-1-55844-212-2.

15. Huchzermeyer, M.; Karam, A. Informal Settlements: A Perpetual Challenge; University of Cape Town Press: Cape Town, South Africa, 2007; ISBN 1-9197-1394-8.

16. Un-Habitat. United Nations Human Settlements Programme. In Enhancing Urban Safety and Security: Global Report on Human Settlements 2007; Earthscan: London, UK, 2007; ISBN 971-1-84407-475-4.

17. IPCC. Climate Change 2014: Mitigation of Climate Change. Contribution of Working Group III to the Fifth Assessment Report of the Intergovernmental Panel on Climate Change; Edenhofer, O.R., Pichs-Madruga, Y., Sokona, E., Farahani, S., Kadner, K., Seyboth, A., Adler, I., Baum, S., Brunner, P., Eickemeier, B., et al., Eds.; Cambridge University Press: Cambridge, UK, 2014.

18. Hale, J.D.; Daies, G.; Fairbrass, A.J.; Matthews, T.J.; Rogers, C.D.F.; Sadler, J.P. Mapping Lightscape: Spatial Patterning of Artificial Lightinh in a Urban Landscape. PLoS ONE 2013, 8, e61460. [CrossRef] [PubMed]

19. Wanvik, P.O. Effects of road lighting: An analysis based on Dutch accident statistics 1987-2006. Accid. Anal. Prev. 2009, 41, 123-128. [CrossRef]

20. Uddin, M.; Huynh, N. Truck-involved crashes injury severity analysis for different lighting conditions on rural and urban roadways. Accid. Anal. Prev. 2017, 108, 44-55. [CrossRef] 
21. Zhang, Y.; Lu, H.; Qu, W. Geographical detection of traffic accidents spatial stratified heterogeneity and influence factors. Int. J. Environ. Res. Public Health 2020, 17, 572. [CrossRef]

22. Gould, M.; Poulter, D.R.; Helman, S.; Wann, J.P. Judgments of approach speed for motorcycles across different lighting levels and the effect of an improved tri-headlight configuration. Accid. Anal. Prev. 2012, 48, 341-345. [CrossRef]

23. Wood, J.M.; Isoardi, G.; Black, A.; Cowling, I. Night-time driving visibility associated with LED streetlight dimming. Accid. Anal. Prev. 2018, 121, 295-300. [CrossRef] [PubMed]

24. Bozorg, S.; Tetri, E.; Kosonen, I.; Luttinen, T. The Effect of Dimmed Road Lighting and Car Headlights on Visibility in Varying Road Surface Conditions. LEUKOS-J. Illum. Eng. Soc. North Am. 2018, 14, $259-273$. [CrossRef]

25. Setyaningsih, E.; Putranto, L.S.; Soelami, F.N. Analysis of the visual safety perception and the clarity of traffic signs and road markings in the presence of road lighting in straight and curved road. MATEC Web Conf. 2018, 181, 04001. [CrossRef]

26. Fotios, S. A review of design recommendations for P-class road lighting in European and CIE documents-Part 1: Parameters for choosing a lighting class. Lighting Res. Technol. 2019. [CrossRef]

27. Chawuthai, R. Monitoring roadway lights and pavement defects for nighttime street safety assessment by sensor data analysis and visualization. Sens. Mater. 2018, 30, 2267-2279. [CrossRef]

28. Longcore, T.; Rich, C. Ecological light pollution. Front. Ecol. Environ. 2004, 2, 191-198. [CrossRef]

29. Bruce-White, C.; Shardlow, M. A Review of the Impact of Artificial Light on Invertebrates; Buglife: Peterborough, UK, 2011; p. 32.

30. Gallaway, T.; Olsen, R.N.; Mitchell, D.M. The economics of global light pollution. Ecol. Econ. 2010, 69, 658-665. [CrossRef]

31. The European PPP Expertise Centre (EPEC). Energy Efficient Street Lighting: Guidelines; World Bank Group: Washington, DC, USA, 2010.

32. Mohamed, S. Smart street lighting control and monitoring system for electrical power saving by using VANET. Int. J. Commun. Netw. Syst. Sci. 2013, 6, 351-360. [CrossRef]

33. Ozadowicz, A.; Grela, J. Energy Saving in the street lighting control system-A new approach based on the EN-15232 standard. Energy Effic. 2017, 10, 563. [CrossRef]

34. Crisp, V.H.C.; Henderson, G. The energy management of artificial lighting use. Lighting Res. Technol. 1982, 14, 193-206. [CrossRef]

35. Elvidge, C.; Baugh, K.; Hobson, V.; Kihn, E.; Kroehl, H.; Davis, E.; Cocero, D. Satellite inventory of human settlements using nocturnal radiation emissions: A contribution for the global toolchest. Glob. Chang. Biol. 1997, 3, 387-395. [CrossRef]

36. Elvidge, C.D.; Cinzano, P.; Pettit, D.R.; Arvesen, J.; Sutton, P.; Small, C.; Nemani, R.; Longcore, T.; Rich, C.; Safran, J.; et al. The Nightsat mission concept. Int. J. Remote Sens. 2007, 28, 2645-2670. [CrossRef]

37. Sutton, P.C.; Taylor, M.J.; Anderson, S.; Elvidge, C.D. Sociodemographic Characterization of Urban Areas Using Nighttime Imagery, Google Earth, Landsat and "Social" Ground Truthing; Weng, Q., Quattrochi, D., Eds.; Urban Remote Sensing; CRC Press: Boca Raton, FA, USA, 2007; pp. 291-310.

38. Levin, N.; Duke, Y. High spatial resolution night-time light images for demographic and socio-economic studies. Remote Sens. Environ. 2012, 119, 1-10. [CrossRef]

39. Barducci, A.; Marcoionni, P.; Pippi, I.; Poggesi, M. Effects of light pollution revealed during a nocturnal aerial survey by two hyperspectral imagers. Appl. Opt. 2003, 42, 4349-4361. [CrossRef] [PubMed]

40. Kuechly, H.U.; Kyba, C.C.; Ruhtz, T.; Lindemann, C.; Wolter, C.; Fischer, J.; Hölker, F. Aerial survey and spatial analysis of sources of light pollution in Berlin, Germany. Remote Sens. Environ. 2012, 126, 39-50. [CrossRef]

41. Wu, J.G.; Jenerette, G.D.; Buyantuyev, A.; Redman, C.L. Quantifying spatiotemporal patterns of urbanization: The case of the two fastest growing metropolitan regions in the United States. Ecol. Complex. 2011, 8, 1-8. [CrossRef]

42. Forman, R.T.T.; Godron, M. Landscape Ecology; Wiley: New York, NY, USA, 1986; p. 619.

43. Schneider, A.; Woodcock, C.E. Compact, dispersed, fragmented, extensive? A comparison of urban growth in twenty-five global cities using remotely sensed data, pattern metrics and census information. Urban Stud. 2008, 45, 659-692. 
44. Doll, C. Thematic Guide to Night-time Light Remote Sensing and Its Applications; CIESIN: New York, NY, USA, 2008; p. 4.

45. Luginbuhl, C.B.; Lockwood, G.W.; Davis, D.R.; Pick, K.; Selders, J. From The Ground Up I: Light Pollution Sources in Flagstaff, Arizona. Publ. Astron. Soc. Pac. 2009, 121, 185-203. [CrossRef]

46. ILE. Guidance Notes for the Reduction of Obstructive Light; The Institution of Lighting Engineers: Warwickshire, UK, 2005.

47. Morgan-Taylor, M. Light Pollution and Nuisance: The Enforcement Guidance for Light as a Statutory Nuisance. J. Plan. Environ. Law 2006, 8, 1114-1127.

48. Flanders Government. Order of the Flemish Government of 1 June 1995 concerning General and Sectoral provisions relating to Environmental Safety: Chapter 4.6; Control of nuisance due to light; Flanders Government: Brussels, Belgium, 1995.

49. Fernandes Carvalho, D.; Ferrari, P.; Sisinni, E.; Depari, A.; Rinaldi, S.; Pasetti, M.; Silva, D. A test methodology for evaluating architectural delays of LoRaWAN implementations. Pervasive Mob. Comput. 2019, 56, 1-17. [CrossRef]

50. CIE International Commission on Illumination. CIE 194:2011: On Site Measurement of the Photometric Properties of Road and Tunnel Lighting; Peter Blattner: Hochdorf, Switzerland, 2011; ISBN 9783901906923.

51. Leccese, F.; Salvadori, G.; Rocca, M. Critical analysis of the energy performance indicators for road lighting systems in historical towns of central Italy. Energy 2017, 138, 616-628. [CrossRef]

52. Stevens, R.G. Light-at-night, circadian disruption and breast cancer: Assessment of existing evidence. Int. J. Epidemiol. 2009, 38, 963-970. [CrossRef] [PubMed]

53. Cinzano, P.; Falchi, F.; Elvidge, C.D. The first World Atlas of the artificial night sky brightness. Mon. Not. Royal Astron. Soc. 2001, 328, 689-707. [CrossRef]

54. Mizon, B. Light Pollution Responses and Remedies; Springer: London, UK, 2002; p. 216.

55. Imhoff, M.L.; Lawrence, W.T.; Stutzer, D.C.; Elvidge, C.D. A technique for using composite DMSP/OLS “city lights" satellite data to map urban area. Remote Sens. Environ. 1997, 61, 361-370. [CrossRef]

56. Small, C.; Pozzi, F.; Elvidge, C.D. Spatial analysis of global urban extent from DMSP-OLS night lights. Remote Sens. Environ. 2005, 96, 277-291. [CrossRef]

57. Land SAT. Available online: https://www.sciencedirect.com/topics/earth-and-planetary-sciences/landsat (accessed on 19 March 2020).

58. Sutton, P.; Roberts, D.; Elvidge, C.; Baugh, K. Census from Heaven: An estimate of the global human population using night-time satellite imagery. Int. J. Remote. Sens. 2001, 22, 3061-3076. [CrossRef]

59. Hölker, F.; Moss, T.; Griefahn, B.; Kloas, W.; Voigt, C.C.; Henckel, D.; Hänel, A.; Kappeler, P.M.; Völker, S.; Schwope, A.; et al. The Dark Side of Light: A Transdisciplinary Research Agenda for Light Pollution Policy. Ecol. Soc. 2010, 15, 13. [CrossRef]

60. Massey, P.; Foltz, C.B. The Spectrum of the Night Sky over Mount Hopkins and Kitt Peak: Changes after a Decade. Publ. Astron. Soc. Pac. 2000, 112, 566-573. [CrossRef]

61. Davoudian, N. Urban Lighting for People: Evidence-Based Lighting Design for the Built Environment; RIBA Publishing: London, UK, 2018; ISBN 978-1859468210.

62. Lyytimaki, J.; Tapio, P.; Assmuth, T. Unawareness in environmental protection: The case of light pollution from traffic. Land Use Policy 2012, 29, 598-604. [CrossRef]

63. Falchi, F.; Cinzano, P.; Elvidge, C.D.; Keith, D.M.; Haim, A. Limiting the impact of light pollution on human health, environment and stellar visibility. J. Environ. Manag. 2011, 92, 2714-2722. [CrossRef]

64. Cinzano, P. Recent progresses on a second world atlas of the night-sky brightness, LPTRAN/LPDART realistic models, tomography of light pollution, accurate validation methods and extended satellite data analysis. In Proceedings of the Starlight 2007 Conference, La Palma, Spain, 19-20 April 2007.

65. Night Earth map. Available online: www.nightearth.com (accessed on 24 June 2019).

66. Streetlight-EPC Project, Triggering the market uptake of Energy Performane Contracting through street lighting refurbishment, Co-funded by the Intelligent Energy Europe Programme of European Union. Available online: http://www.streetlight-epc.eu/ (accessed on 19 March 2020).

67. Beccali, M.; Bonomolo, M.; Leccese, F.; Lista, D.; Salvadori, G. On the impact of safety requirements, energy prices and investment costs in street lighting refurbishment design. Energy 2018, 165, 739-759. [CrossRef]

68. Lv, Z.; Li, X.; Zhang, B.; Wang, W.; Zhu, Y.; Hu, J.; Feng, S. Managing Big City Information Based on WebVRGIS. IEEE Access 2016, 4, 407-415. [CrossRef] 
69. Li, M.; Lenzen, M.; Keck, F.; McBain, B.; Rey-Lescure, O.; Li, B.; Jiang, C. GIS-Based Probabilistic Modeling of BEV Charging Load for Australia. IEEE Trans. Smart Grid 2019, 10, 3525-3534. [CrossRef]

70. Re Cecconi, F.; Moretti, N.; Dejaco, M.C.; Maltese, S.; Tagliabue, L.C. Community involvement in urban maintenance prioritization. In Proceedings of the 2017 AEIT International Annual Conference, Cagliari, Italy, 20-22 September 2017; pp. 1-6. [CrossRef]

71. European Commission. Annual Accident Report 2017; European Road Safety Observatory: Bruxelles, Belgium, 2017; Available online: www.erso.eu (accessed on 20 March 2020).

72. Incidenti stadali Comune di Milano, Opena Data. Available online: https://www.dati.lombardia.it/Sicurezza/ INCIDENTI-STRADALI-nel-COMUNE-MILANO/y7qm-hfqy (accessed on 19 March 2020).

73. Portale Open Data Comune di Milano. Available online: http://dati.comune.milano.it/dataset/ds177trafficotrasporti-incidenti-stradali-persone-infortunate-mese-zona (accessed on 19 March 2020).

74. Kumar, S.; Deshpande, A.; Ho, S.S.; Ku, J.S.; Sarma, S.E. Urban Street Lighting Infrastructure Monitoring Using a Mobile Sensor Platform. IEEE Sens. J. 2016, 16, 12. [CrossRef]

75. Bellagente, P.; Ferrari, P.; Flammini, A.; Rinaldi, S. Adopting IoT framework for Energy Management of Smart Building: A real test-case. In Proceedings of the 2015 IEEE 1st International Forum on Research and Technologies for Society and Industry, Turin, Italy, 16-18 September 2015; RTSI 2015-Proceedings. pp. 138-143.

76. Cui, Y.; Ge, S.S. Autonomous vehicle positioning with gps in urban canyon environments. IEEE Trans Robot Autom. 2003, 19, 15-25.

77. EN 13201-3:2015: Road lighting-Part 3: Calculation of performance; NSAI Standard: Dublin, Ireland, 2015.

78. NOAO - National Optical Astronomy Observatory, Recommended Light Levels (Illuminance) for Outdoor and Indoor Venues. Available online: https://www.noao.edu/education/QLTkit/ACTIVITY_Documents/ Safety/LightLevels_outdoor+indoor.pdf (accessed on 19 March 2020).

79. Hu, X.; Qian, K. Optimal design of optical system for LED road lighting with high illuminance and luminance uniformity. Appl. Opt. 2013, 52, 5888-5893. [CrossRef]

80. Feng, Z.; Luo, Y.; Han, Y. Design of LED freeform optical system for road lighting with high luminance/illuminance ratio. Opt. Express 2010, 18, 22020-22031. [CrossRef]

81. Schreuder, D.A. Road Lighting for Safety; Inst of Civil Engineers Pub: London, UK, 1998.

82. European Committee for Standardization (CEN) CEN-EN 13201-4: 2015-Methods of Measuring Lighting Performance; European Committee for Standardization: Brussels, Belgium, 2015. 